\title{
Simulation study of near-Earth space disturbances: 1. magnetic storms
}

\author{
Yusuke Ebihara(i)
}

\begin{abstract}
A magnetic storm is the world-wide geomagnetic disturbance taking place in near-Earth space environment, lasting for a few days. Geomagnetic fields can be depressed by $~ 1 \%$ on the ground for large magnetic storms. The prime cause of the long-lasting, world-wide geomagnetic disturbance is the development of the ring current that surrounds the Earth. The ring current is an electric current carried by charged particles. Thus, the growth and decay of the ring current correspond to accumulation and loss of the ring current particles, respectively. The ring current is strong enough to modulate near-Earth space environment, and leads to many observable effects. In this sense, the ring current can be regarded as an important mediator in the near-Earth space environment. Here, the dynamics and structure of the ring current and its active role are briefly reviewed on the basis of numerical simulation results.
\end{abstract}

Keywords: Magnetic storms, Computer simulation, Magnetosphere, lonosphere, Inner magnetosphere, Ring current

\section{Introduction}

Magnetic storms are characterized by irregular disturbance of the geomagnetic field. A magnetic storm starts with an initial phase, followed by a main phase and a recovery phase. The initial phase is characterized by a sharp increase in the horizontal component (H-component) of the geomagnetic field, but the initial phase is not always involved in all the magnetic storms. The main phase is characterized by a substantial decrease in the geomagnetic field, lasting for a few hours, or more (Gonzalez et al. 1994). Magnetic storms were first recognized by von Humboldt (1808) who observed magnetic declination in Berlin (Lakhina and Tsurutani 2016). Nowadays, the magnetic storms are known as world-wide magnetic disturbance. In 1917, Schmidt postulated the existence of a ring current encircling the Earth to cause the decrease in the $\mathrm{H}$-component of the magnetic field (Egeland and Burke 2012). Satellite observations confirmed the existence of the ring current (Frank 1967; Smith and Hoffman 1973; Lui et al. 1987; Le et al. 2004). In the recovery phase, the $\mathrm{H}$-component of the geomagnetic field returns to the pre-storm level, which is primarily caused by the decay of the ring current.

Correspondence: ebihara@rish.kyoto-u.ac.jp

Research Institute for Sustainable Humanosphere, Kyoto University, Gokasho, Uji, Kyoto 611-0011, Japan

Springer Open
The term "ring current" gives the impression that the ring current is completely symmetric about the dipole axis of the Earth. However, according to ground-based observations, the negative disturbance of the magnetic field depends on a magnetic local time (MLT), suggesting asymmetric ring current (Akasofu and Chapman 1964). This is confirmed by satellite observations (Le et al. 2004). To provide a unified measure of the strength of the magnetic disturbance, a Dst index (disturbance storm time index) is invented (Sugiura 1964). The Dst index is basically a weighted average of $\Delta \mathrm{H}-\mathrm{H}_{\text {base }}$ observed at four different longitudes at low latitudes (Honolulu, San Juan, Hermanus, and Kakioka), where $\mathrm{H}_{\text {base }}$ is the baseline for quiet days (Sugiura and Kamei 1991). The Dst index is reasonably predicted by an empirical formula, which is a function of the solar wind speed, the solar wind density, and the southward component of IMF Bz (Burton et al. 1975). The Burton et al.'s formula is derived based on an energy balance equation. To understand the growth and decay of the ring current deeply, one has to take into consideration the particles that are the carrier of the ring current.

The major carrier of the storm-time ring current is known to be ions with energy of tens of keV (Frank 1967; Smith and Hoffman 1973). The AMPTEE/CCE satellite measured substantial contribution from $\mathrm{O}^{+}$to the storm-time ring current (Hamilton et al. 1988). This is a 
striking finding in the ring current research because it implies that the source of the ring current particles is not only the Sun, but also the Earth. As for quiet time (non-storm time), the ring current consists of ions with energy greater than $100 \mathrm{keV}$. This means that the ring current always exists regardless of magnetic storms. Investigation of the growth and decay of the ring current is equivalent to investigating the accumulation and loss of the ions with energy of the order of tens of $\mathrm{keV}$ in the inner magnetosphere.

The charged particles trapped by Earth's magnetic field undergo three different types of motion, gyromotion, bounce motion along a field line between two mirror points, and drift motion perpendicular to the magnetic field. The current density is defined by the electric current per unit area of cross section. When the first adiabatic invariant is conserved, the current density is given by summing up the currents associated with gyromotion, grad-B drift and curvature drift as (Parker 1957)

$$
\mathbf{J}=\frac{\mathbf{B}}{B^{2}} \times\left[\nabla P_{\perp}+\frac{P_{\|}-P_{\perp}}{B^{2}}(\mathbf{B} \cdot \nabla) \mathbf{B}\right],
$$

where $B, P_{\perp}$, and $P_{\|}$are the magnetic field, perpendicular plasma pressure, and parallel plasma pressure, respectively. Observations show that the first term of the right-hand side of Eq. (1) dominates the second one, although the second one is non-negligible in the ring current (Lui et al. 1987). The first term is called "diamagnetic current," and is associated with gyromotion of the particles. The peak of the pressure takes place at $L \sim 2-3$ (Lui et al. 1987). Because of the dominance of the diamagnetic current, the ring current flows westward in the outer region, and flows eastward in the inner region. The distribution of the current density is investigated by Le et al. (2004) in detail.

The plasma pressure is given by

$$
\begin{aligned}
& P_{\perp}=\int \frac{1}{2} m v^{2} f(\mathbf{v}) \sin ^{2} \alpha d \mathbf{p}, \\
& P_{\|}=\int m v^{2} f(\mathbf{v}) \cos ^{2} \alpha d \mathbf{p},
\end{aligned}
$$

where $m, v, f, \alpha$, and $\mathbf{p}$ are mass, velocity, phase space density, pitch angle, and momentum vector, respectively. For gyrotropic plasma, $d \mathbf{p}=2 \pi m^{3} v^{2} \sin \alpha d \alpha d v$. The phase space density $f$ is related to the directional differential flux $j$ as $f=j / p^{2}$. According to Liouville's theorem, the phase space density must be conserved when source and loss of particles are absent.

Equations (1) and (2) imply that understanding the ring current is equivalent to understand the phase space density of the charged particles. Because motion of charge particles depend on kinetic energy and pitch angle as well as local magnetic and electric fields, it is essential to track motion of charged particles properly for the purpose of understanding the ring current and the magnetic storms.

\section{Storm main phase (development of ring current)}

The ring current is known to develop when the interplanetary magnetic field (IMF) is southward (Kokubun 1972). Coronal mass ejection (CME) and a corotating interaction region (CIR) are thought to deliver prolonged southward IMF (Tsurutani et al. 1988). A magnetic cloud is embedded in the ejecta of CME. In front of the magnetic cloud, the solar wind is compressed. This compressed region is called a sheath, and strong southward IMF can be formed. When the strong southward IMF is embedded in either the sheath or the magnetic cloud, a magnetic storm occurs. The magnetic storm would develop in a two-step manner when the strong southward IMF is embedded in both the sheath and the magnetic cloud (Kamide et al. 1998). The CIR is accompanied with high speed solar wind streams originating from a coronal hole on the surface of the Sun. In the CIR, IMF is highly fluctuated (Tsurutani and Gonzalez 1987). The southward component of the fluctuated IMF can cause a magnetic storm. Statistical studies show that the CME-driven magnetic storms tend to be larger than the CIR-driven magnetic storms in terms of the Dst index (Borovsky and Denton 2006; Denton et al. 2006).

The fundamental process for the development of the ring current is the accumulation of particle energy in the inner magnetosphere where the Earth's dipolar magnetic field dominates (Dessler and Parker 1959; Sckopke 1966). There are two competing processes for the accumulation of the particle energy. One is that the particle energy is accumulated by a succession of substorms (Akasofu 1968). Hot plasma is known to be injected into the inner magnetosphere by short-lived impulsive electric field at the substorm expansion (DeForest and McIlwain 1971; Kamide and McIlwain 1974). If the substorm injection occurs frequently with a sufficiently short interval, the particle energy would increase stepwisely. The other process is that hot plasma is transported by the persistent, large-scale convection electric field (Axford 1969). As the particles move into the inner magnetosphere, they adiabatically gain kinetic energy, resulting in a substantial increase in the net particle energy. In both the processes, dawn-dusk electric field is responsible for the earthward transport of the particles stored in the plasma sheet on the nightside. A question arises: What is the essential cause of the storm-time ring current?

In 1940s-1950s, Hannes Alfvén divided motion of charged particles into gyromotion and its guiding center motion. Introducing a uniform electric field and the dipole magnetic field, he suggested drift paths of particles 
in the equatorial plane, and field-aligned current associated with the asymmetric paths of them (Egeland and Burke 2012). The invention of the guiding-center approximation helps reduce computational cost significantly. The state of charged particles is described by six dimensional independent parameters, that is, three for real space and three for momentum space. With the guiding-center approximation, the number of the dimension can be reduced to five because information about gyro phase is lost. With the bounce-averaged approximation (Roederer 1970), the number of the dimension can be reduced to four because information about gyro phase and bounce phase are lost. The bounce-averaged approximation has been preferred to track motion of the charged particles in the inner magnetosphere because the gyro phase and the bounce phase do not matter in many cases.

When there are no sink and source, the number of particles must be conserved in phase space. One of the practical schemes to solve the evolution of the phase space density is based on the Boltzmann equation (Fok et al. 1995; Jordanova et al. 1996; Kozyra et al. 1998b; Liemohn et al. 1999). Another scheme is based on weighted particle tracing (Ebihara and Ejiri 1998; Chen et al. 1998; Ebihara and Ejiri 2000), which is similar to the ones that have employed to calculate the evolution of the ring current in terms of energy (Lee et al. 1983; Wodnicka 1989; Takahashi et al. 1990). The Rice Convection Model solves the evolution of the particle content in a flux tube (Toffoletto et al. 2003)

Simulation studies show that the fundamental evolution of the ring current ions can be achieved when the dipole magnetic field, the convection electric field, and the corotation electric field are taken into consideration. The strength of the convection electric field is known to increase when the southward component of the IMF is strong and the solar wind speed is high (Matsui et al. 2013). The total potential drop of the convection electric field is $\sim 20 \mathrm{kV}$ for quiet time, and is $\sim 200 \mathrm{kV}$ and more during the magnetic storms (Ebihara et al. 2005a; Hairston et al. 2005). In the equatorial plane, the direction of the convection electric field is duskward, corresponding to the sunward $E \times B$ drift. A simple form of the convection electric field (Volland 1973; Stern 1975) has been widely used to describe the transport of charged particles in the inner magnetosphere, which is given by

$$
\Phi_{c v}=A\left(\frac{r}{a}\right)^{\gamma} \sin \phi
$$

where $A$ is the intensity of the convection electric potential, $a$ is the Earth's radius, $\gamma$ is a shielding factor, and $\phi$ is MLT. The convection electric field is uniform when $\gamma=1$. The moderately shielded condition, in which $\gamma=2$, is often used by simulations. Ejiri (1981) suggested that $\gamma$ depends on the Kp index as $\gamma=7.3 / \mathrm{Kp}$.

The corotation electric field arises from the Earth's rotation with partially ionized atmosphere. The electric potential of the corotation electric field is given by

$$
\Phi_{c r}(r)=-\int_{\infty}^{r} \mathbf{E} \cdot d \mathbf{r}
$$

where

$$
\mathbf{E}=-(\boldsymbol{\Omega} \times \mathbf{r}) \times \mathbf{B},
$$

and $\Omega$ is the angular frequency of Earth's rotation. In the equatorial plane, Eq. (4) yields

$$
\Phi_{c o}=\int_{\infty}^{r} \Omega r B d r .
$$

Assuming the dipole magnetic field,

$$
B=B_{0} \frac{a^{3}}{r^{3}},
$$

where $B_{0}$ is the magnetic field at the equator. Substituting Eq. (7) into Eq. (6), we have

$$
\begin{aligned}
\Phi_{c o} & =\int_{\infty}^{r} \frac{\Omega B_{0} a^{3}}{r^{2}} d r \\
& =-\frac{\Omega B_{0} a^{3}}{r} .
\end{aligned}
$$

Equation (8) implies that the Earth is negatively charged from ambient in quasi-inertial frame of reference due to Earth's rotation. According to the 12th generation of the International Geomagnetic Reference Field (Thébault et al. 2015), $B_{0}$ is $30,829 \mathrm{nT}$ in 1970 , and $29,868 \mathrm{nT}$ in 2015. The total corotation potential drop is $91 \mathrm{kV}$ in 1970 , and $88 \mathrm{kV}$ in 2015. The decrease in the total potential drop results from the secular variation of the geomagnetic field.

When the first adiabatic invariant $\mu$ is conserved, the bounce-averaged trajectory of a non-relativistic particle follows the equipotential as

$$
q \Phi_{c n}+q \Phi_{c o}+\mu B+\frac{1}{2} m v_{\|}^{2}=\text { const, }
$$

where $q$ is charge, $m$ is mass, and $v_{\|}$is parallel component of the velocity. The bounce-averaged drift velocity for the grad-B and curvature drifts is provided by Roederer (1970). By summing up the $E \times B$ drift velocity and the bounce-averaged drift velocity for the grad- $B$ and curvature drifts, one can trace the motion of charged particles in a time-dependent manner. A precise approximation for the bounce-averaged drift velocity in the dipole magnetic field is given by Ejiri (1978).

Figure 1 shows an example of calculated Dst (SYM-H) values for a large magnetic storm (Ebihara et al. 2005a). SYM-H is essentially equivalent to Dst. The calculation 


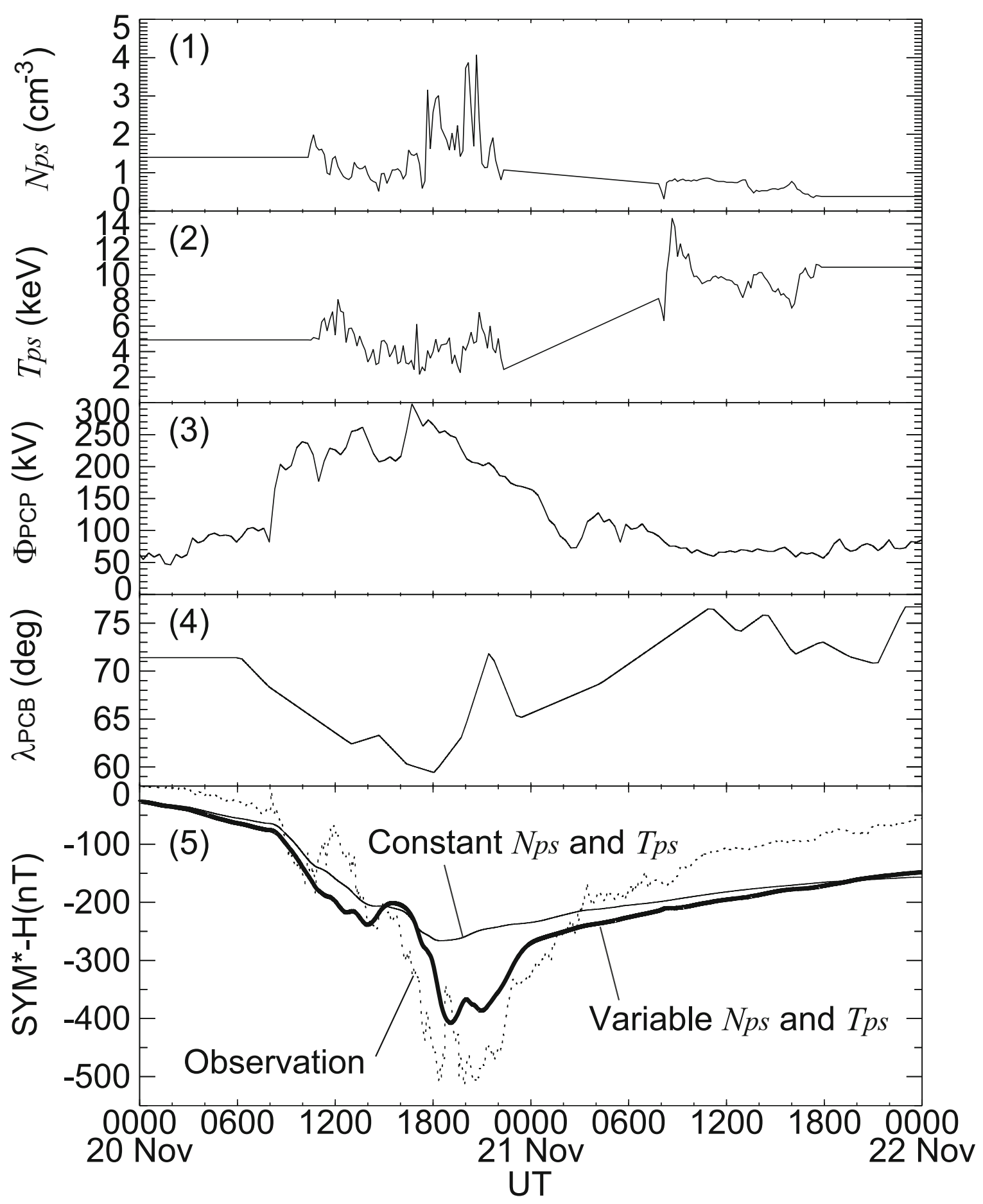

Fig. 1 Simulated storm-time Dst (SYM-H) index during the magnetic storm of 20-21 November 2003. The input parameters (plasma sheet density $N_{\mathrm{ps}}$ plasma sheet temperature $T_{\mathrm{ps} \text {, }}$ strength of the convection electric field $\Phi_{\mathrm{PCP}}$, magnetic latitude of the polar cap boundary at which $\Phi_{\mathrm{PCP}}$ is imposed) used to drive the simulation are summarized in the top 4 panels. (Ebihara et al. 2005a) 


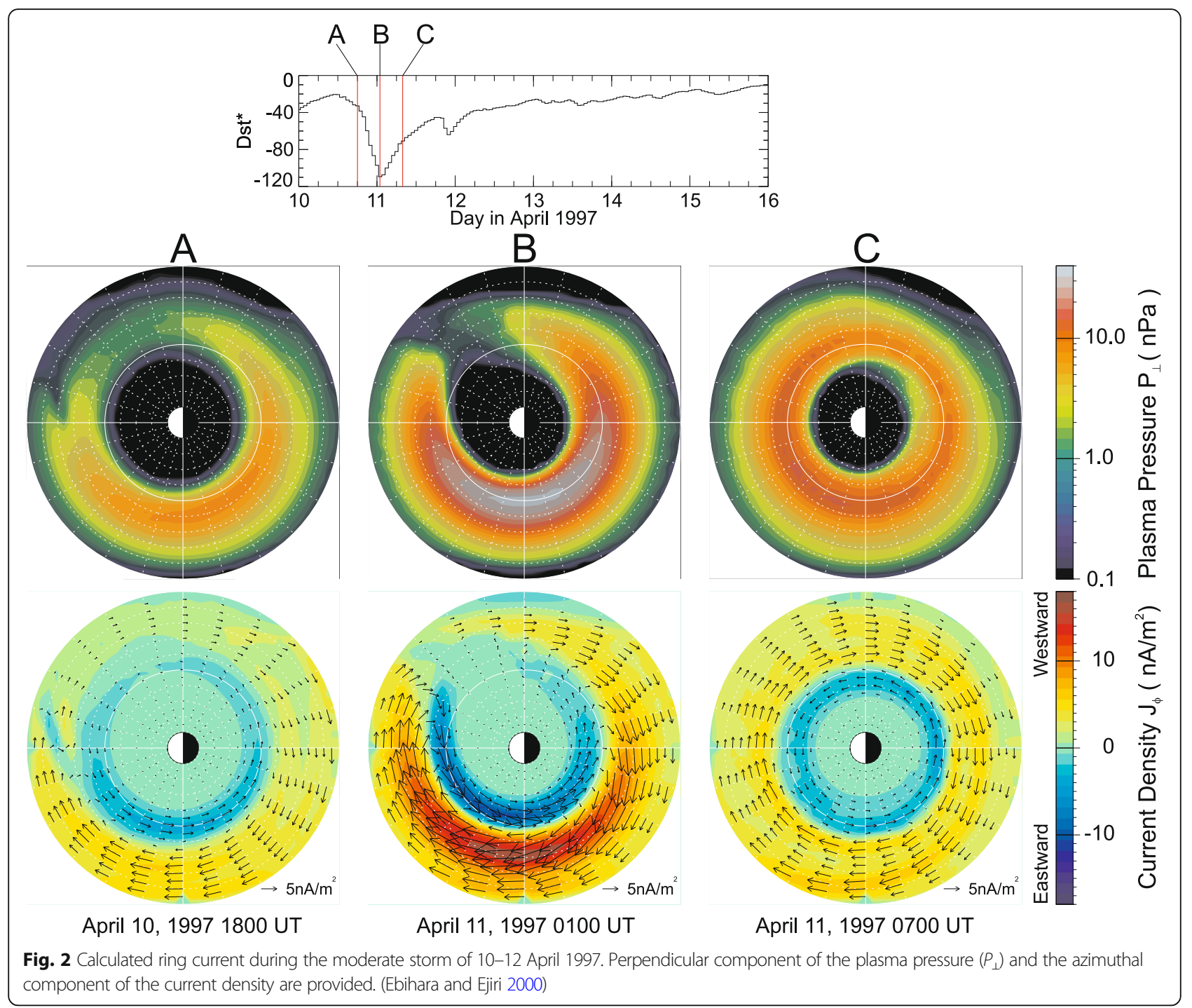

was performed by the comprehensive ring current model (CRCM) (Fok et al. 2001). The electric potential, which depends on the solar wind and IMF (Siscoe 2002), is imposed to the outer boundary of the simulation. The plasma sheet density and temperature measured by geosynchronous satellites are imposed to the outer boundary of the simulation. The calculated Dst (SYM-H) shows a negative excursion, and roughly follows the observed one. When the plasma sheet density and temperature are held constant through the simulation, the amplitude of the negative excursion is much smaller than that observed. This suggests that the intensification of the ring current is caused by not only the enhancement of the convection electric field but also the enhancement of the plasma sheet density and/or temperature (Ebihara and Ejiri 1998; Kozyra et al. 1998b; Ebihara and Ejiri 2000; Liemohn et al. 2001). The plasma sheet density is known to increase when the solar wind density is high (Terasawa et al. 1997; Ebihara and Ejiri 2000). It is thought that the intensity of the ring current is proportional to the plasma sheet density. However, because of the shielding effect described below, the magnitude of the ring current is no longer proportional to the plasma sheet density (Ebihara et al. 2005b).

Figure 2 shows the calculated plasma pressure and the azimuthal component of the current density in the equatorial plane (Ebihara and Ejiri 2000). The dawn-dusk convection electric field, the corotation electric field, and the dipole magnetic are taken into consideration in the simulation. The strength of the convection electric field is changed in accordance with the solar wind parameters. As the storm main phase proceeds (from A to B), the plasma pressure increases in the midnight-dusk sector, whereas it decreases in the noon-dawn sector. Figure 3 shows drift trajectories of the ions originating in the nightside plasma sheet. When the strength of the convection electric field is kept constant (left panel of Fig. 3), the drift paths are 


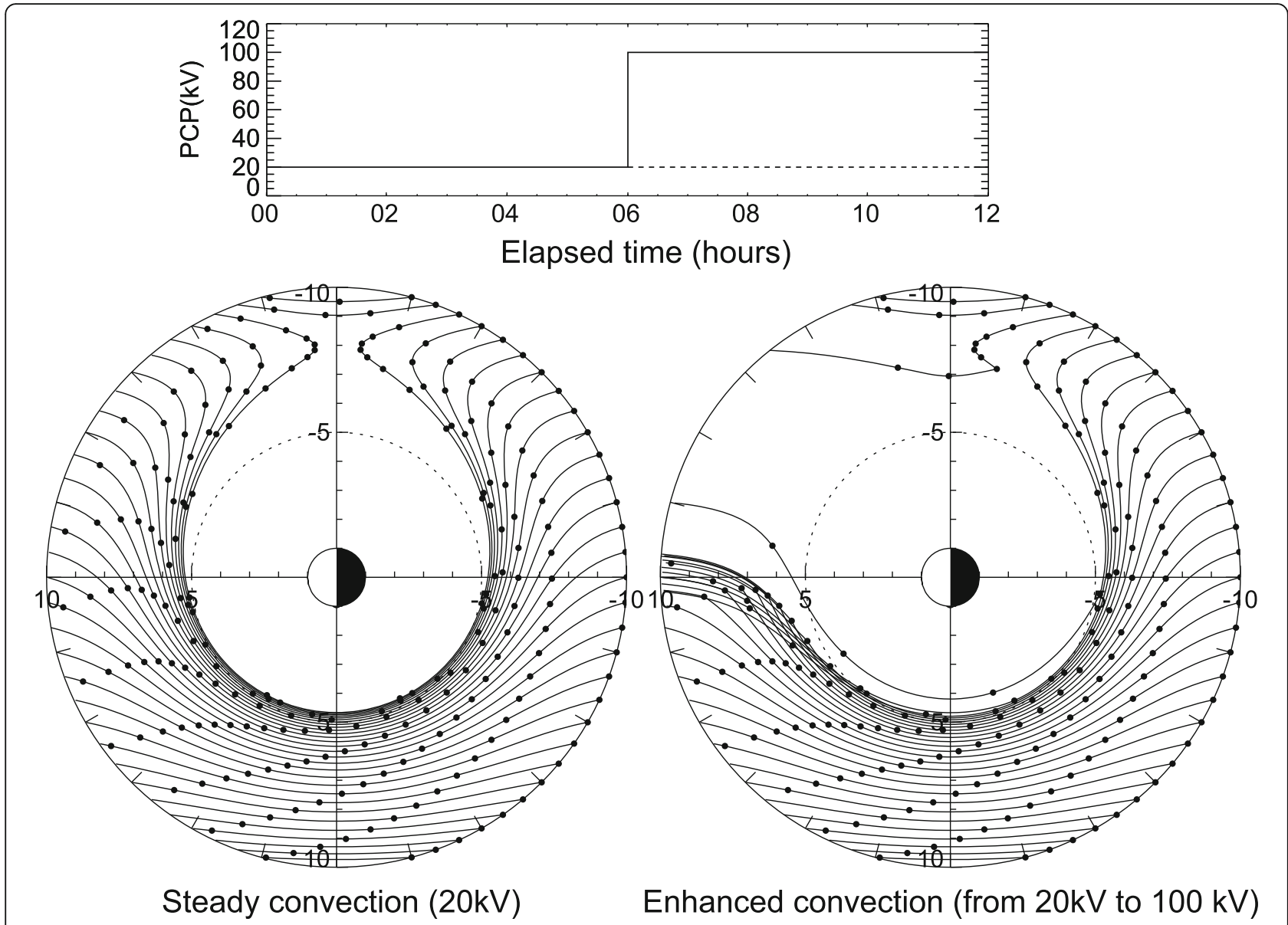

Fig. 3 Bounce-averaged drift trajectories of protons with magnetic moment of $0.030 \mathrm{keV} / \mathrm{nT}$ with initial equatorial pitch angle of $25^{\circ}$ at $L=10 \mathrm{in}$ the presence of the convection electric field, the corotation electric field, and the dipole magnetic field. A filled circle is marked every $1 \mathrm{~h}$ along the trajectory. (Ebihara et al. 2004)

symmetric about the dawn-dusk meridian. After departing the nightside plasma sheet, they gradually penetrate into the inner region. As they approach the Earth, they travel duskward, and gain kinetic energy, resulting in the enhancement of the plasma pressure. After passing through the dusk meridian, they travel dawnward, and lose kinetic energy. An interesting feature is that the plasma pressure decreases in the noon-dawn sector as shown in Fig. $2 b$. This is explained by the change of the drift paths. When the strength of the convection electric is enhanced in the

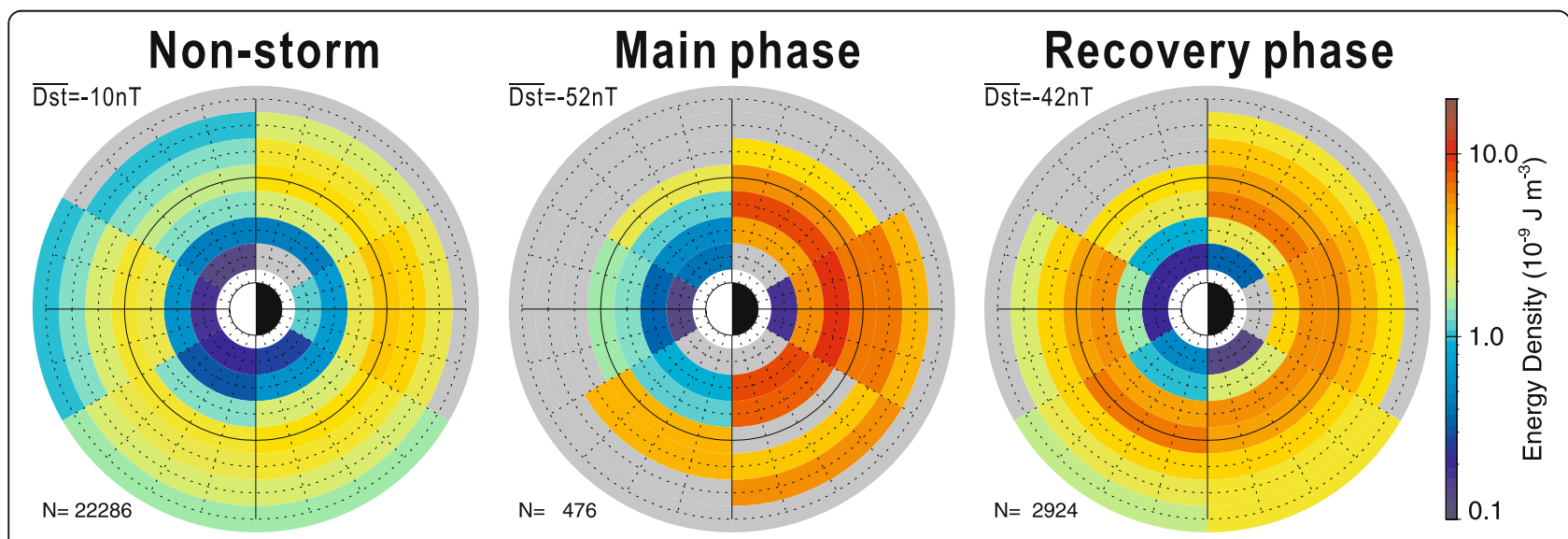

Fig. 4 Energy density of protons with energy 1-200 keV observed by the Polar satellite near the equatorial plane. (After Ebihara et al. 2002) 
Table 1 Decay processes for ring current (Ebihara and Ejiri 2003)

\begin{tabular}{|c|c|c|}
\hline Process & Region or cause & Fate \\
\hline Charge exchange & Geocorona & Energetic neutral atom (Dessler and Parker 1959) \\
\hline Coulomb collision & Plasmasphere & $\begin{array}{l}\text { Precipitation into ionosphere (Wentworth et al. 1959; } \\
\text { Fok et al. 1991; Jordanova et al. 1996) }\end{array}$ \\
\hline Wave-particle interaction & $\begin{array}{l}\text { Resonant interaction with } \\
\text { ion cyclotron wave }\end{array}$ & Precipitation into ionosphere (Cornwall et al. 1970) \\
\hline Adiabatic loss cone loss & Inward transport of ions & Precipitation into ionosphere (Jordanova et al. 1996) \\
\hline Field line curvature & Curved magnetic field line & $\begin{array}{l}\text { Precipitation into ionosphere (Sergeev et al. 1983; } \\
\text { Ebihara et al. 2011) }\end{array}$ \\
\hline $\begin{array}{l}\text { Sudden decrease in } \\
\text { plasma sheet density }\end{array}$ & Entire ring current & $\begin{array}{l}\text { Replacement of ring current ions with tenuous ones } \\
\text { (Ebihara and Ejiri 1998) }\end{array}$ \\
\hline
\end{tabular}

course of the earthward drift motion (right panel of Fig. 3), the ions start traveling sunward immediately. In the noondawn sector, the preexisting ions also start traveling sunward, resulting in the removal of the preexisting ones from the noon-dawn sector. The sudden decrease in the ion flux in the noon-dawn sector is observed by global images of energetic neutral atoms when the convection electric field is enhanced (Brandt et al. 2002). The simulation result is also consistent with the magnetic disturbances on the ground (Hashimoto et al. 2002).

The bottom panel of Fig. 2 shows the current density, that is, the electric current per unit area. The westward current flows in the outer region, and the eastward one flows in the inner region. The current density also shows the asymmetric distribution during the main phase,

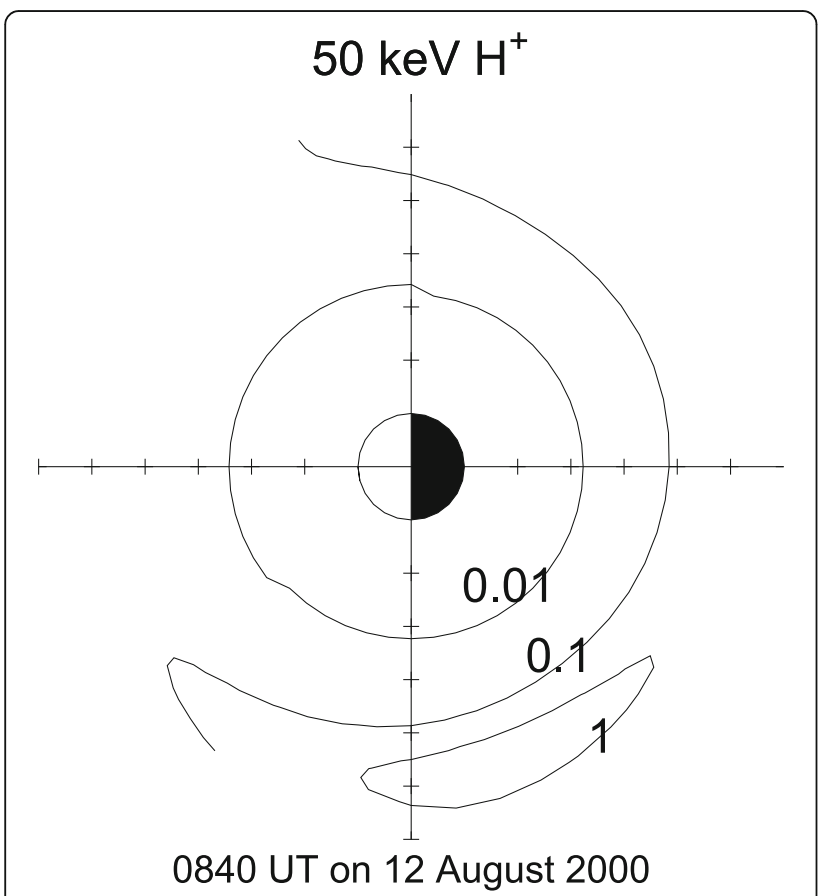

Fig. 5 The ratio of the gyroradius of protons with energy of $50 \mathrm{keV}$ to the curvature radius of the magnetic field line for intense storm. (Ebihara et al. (2011) which is consistent with the observation (Le et al. 2004). Because of the dipolar geometry, the cross-sectional area of the outer region where the westward current flows is larger than the inner region where the eastward current flows. Thus, the net current flowing westward is larger than that flowing eastward (Ebihara and Ejiri 2000). The dominance of the net westward current causes the decrease in the geomagnetic field on the ground.

Figure 4 shows the averaged energy density of the protons with energy from 1 to $200 \mathrm{keV}$ (Ebihara et al. 2002). For isotropic pressure $\left(P_{\perp}=P_{\|}\right)$, the energy density is 1.5 times larger than the plasma pressure. The data was acquired when the Polar satellite traversed the equatorial plane. During the storm main phase, the energy density significantly increases on the nightside, whereas it decreases on the decreases. The increase and decrease in the energy density can be reasonably explained by the intensification and relaxation of the convection electric field as shown in Fig. 2.

In addition to the convective transport, substorm-associated transport has also been simulated (Fok et al. 1999). Fok et al. (1999) calculated the substorm-associated electric field by differentiating empirical magnetic field, and

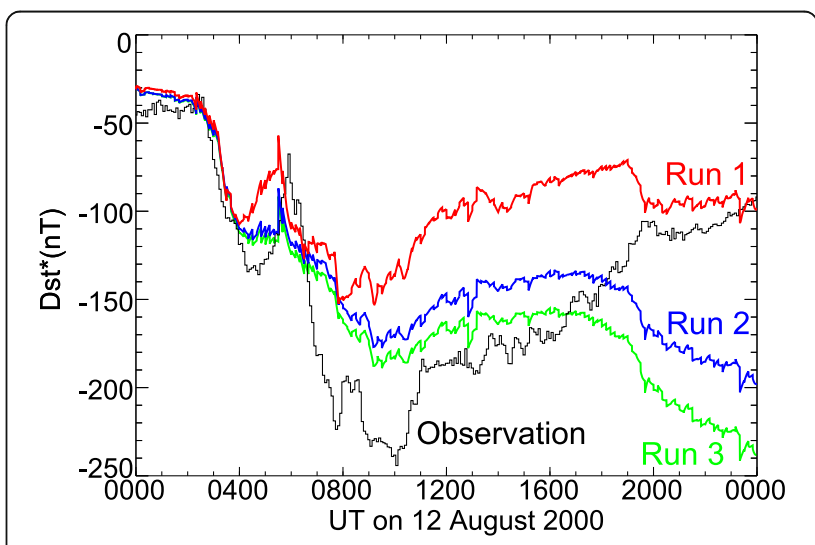

Fig. 6 Calculated Dst for run 1, run 2, and run3. Run 1 considers the charge exchange and the field-line curvature scattering. Run 2 considers the charge exchange only. Run3 considers no loss process. The black line indicates the observed one. Ebihara et al. (2011) 


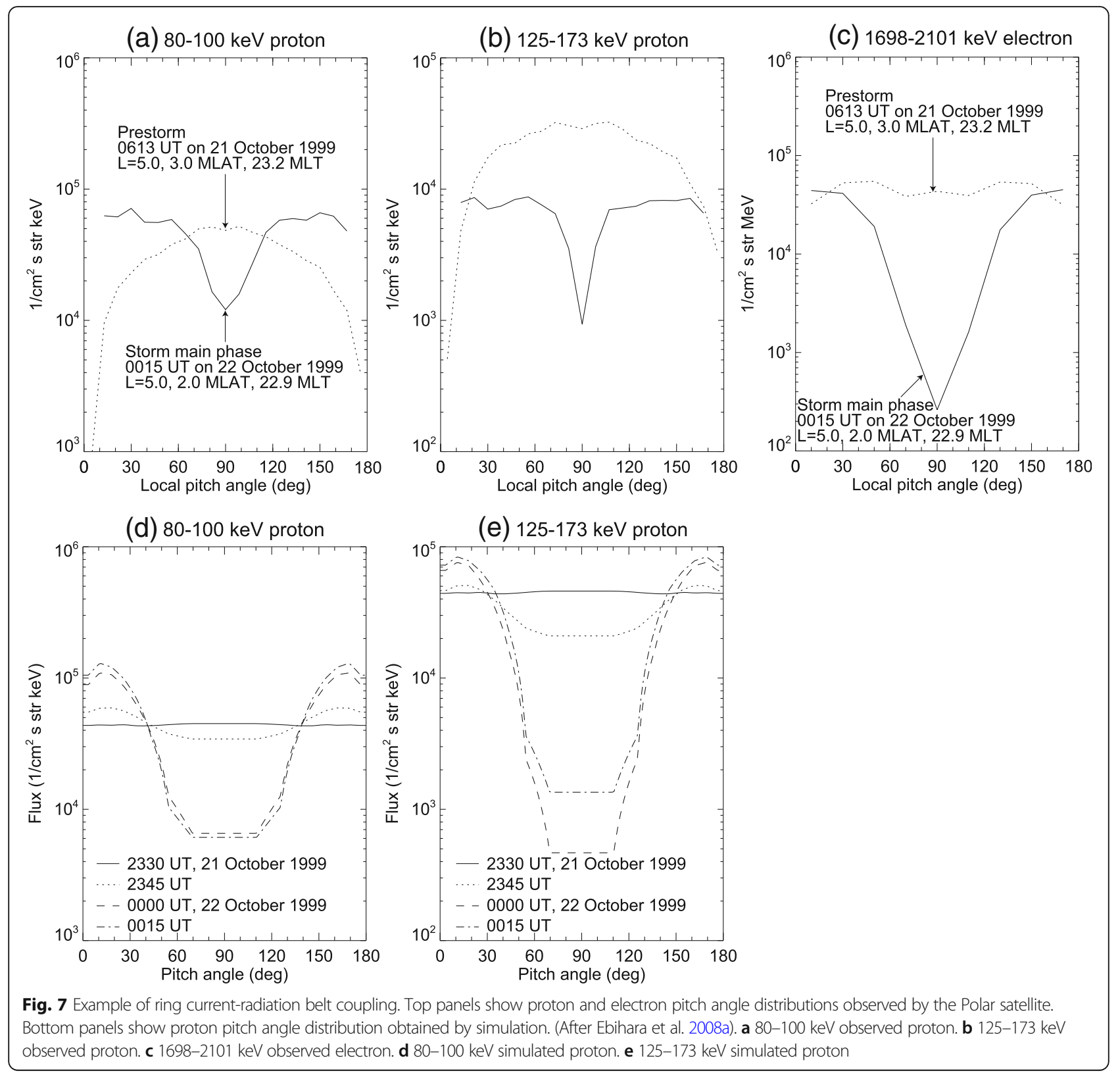

solved the evolution of the phase space density of the ions. The ring current is intensified well when the strong convection electric is incorporated. This suggests that the substorm without enhancement of the convection electric field has little impact on the ring current.

\section{Storm recovery phase (decay of ring current)}

The storm recovery phase is known to start when the southward IMF becomes weak, or turns northward (Burton et al. 1975). The northward turning of IMF results in an immediate reduction of the convection electric field. The characteristic decay time of the Dst value is estimated to be $7.7 \mathrm{~h}$ for the magnetic storms (Burton et al. 1975).
Shorter decay time, less than $1 \mathrm{~h}$, is also suggested for large storms (Macmahon and Llop-Romero 2008). Observations show that the plasma pressure (energy density) of the ring current protons becomes symmetric during the recovery phase as shown in Fig. 4. This symmetrization of the storm-time ring current can be understood to the change in the drift paths of the ions. When the convection electric field becomes weak, the azimuthal drift motion (the grad-B drift and the curvature drift) dominates the $E \times B$ drift. The plasma sheet ions cannot penetrate deep earthward any more, and the ions that had been previously transported to the inner magnetosphere during the main phase cannot escape from the inner magnetosphere. 
Consequently, in the noon-dusk sector, the plasma pressure increases in comparison with the main phase. The simulation results (Fig. 2) are consistent with the observations (Fig. 4). The reduction of the convection electric field, however, cannot result in the net decay of the ring current because most of the particles still remain trapped in the inner magnetosphere (Ebihara and Ejiri 2003). At least, there are six processes that may be related to the decay of the storm-time ring current. They are summarized in Table 1.

Charge exchange is one of the dominant loss process for the ring current ions (Dessler and Parker 1959). The charge exchange frequently occurs where neutral atoms are dense, such as low $L$-shells, and low altitude. According to an empirical model (Rairden et al. 1986), the geocorona density is $660 \mathrm{~cm}^{-3}$ at geocentric distance of 3 Re. At $L=3$, the charge exchange lifetime for $\mathrm{H}^{+}$is $4 \mathrm{~h}$ at $10 \mathrm{keV}$, and $96 \mathrm{~h}$ at $100 \mathrm{keV}$. For $\mathrm{O}^{+}$, it is $16 \mathrm{~h}$ at $10 \mathrm{keV}$, and $11 \mathrm{~h}$ at $100 \mathrm{keV}$ (Ebihara and Ejiri 2003). As the ion travels toward Northern Hemisphere, or Southern Hemisphere along a field line, the ion undergoes short lifetime because of dense neutral atoms. Therefore, the lifetime depends on the equatorial pitch angle. The two-step recovery of Dst is attributed to the lifetime depending on ionic species. On the basis of the observation that $\mathrm{O}^{+}$dominates $\mathrm{H}^{+}$in the storm-time ring current, it is suggested that the first rapid recovery is caused by the charge exchange of $\mathrm{O}^{+}$, followed by the slow recovery caused by the charge exchange of $\mathrm{H}^{+}$(Hamilton et al. 1988). Numerical simulation, however, shows that the charge exchange is insufficient to explain the rapid recovery, and that precipitation into the ionosphere is necessary (Kozyra et al. 1998a). Kozyra et al. (1998a) pointed out that in addition to charge exchange, the precipitation loss is significant for the rapid recovery of Dst. This is supported by the evidence of a filled loss cone observed by satellites (Amundsen et al. 1972; Williams and Lyons 1974; Hultqvist et al. 1976; Sergeev et al. 1983; Walt and Voss 2001). However, the mechanism for the pitch angle scattering that leads to the filled loss cone is not well known.

Coulomb collision with thermal plasma, and resonant interaction with ion cyclotron waves result in the pitch angle scattering, but their role in the overall reduction of the ring current is suggested to be minor (Jordanova et al. 2001). As recently suggested, resonant interaction with ion cyclotron waves may cause pitch angle scattering significantly during extremely intense magnetic storms (Tsurutani

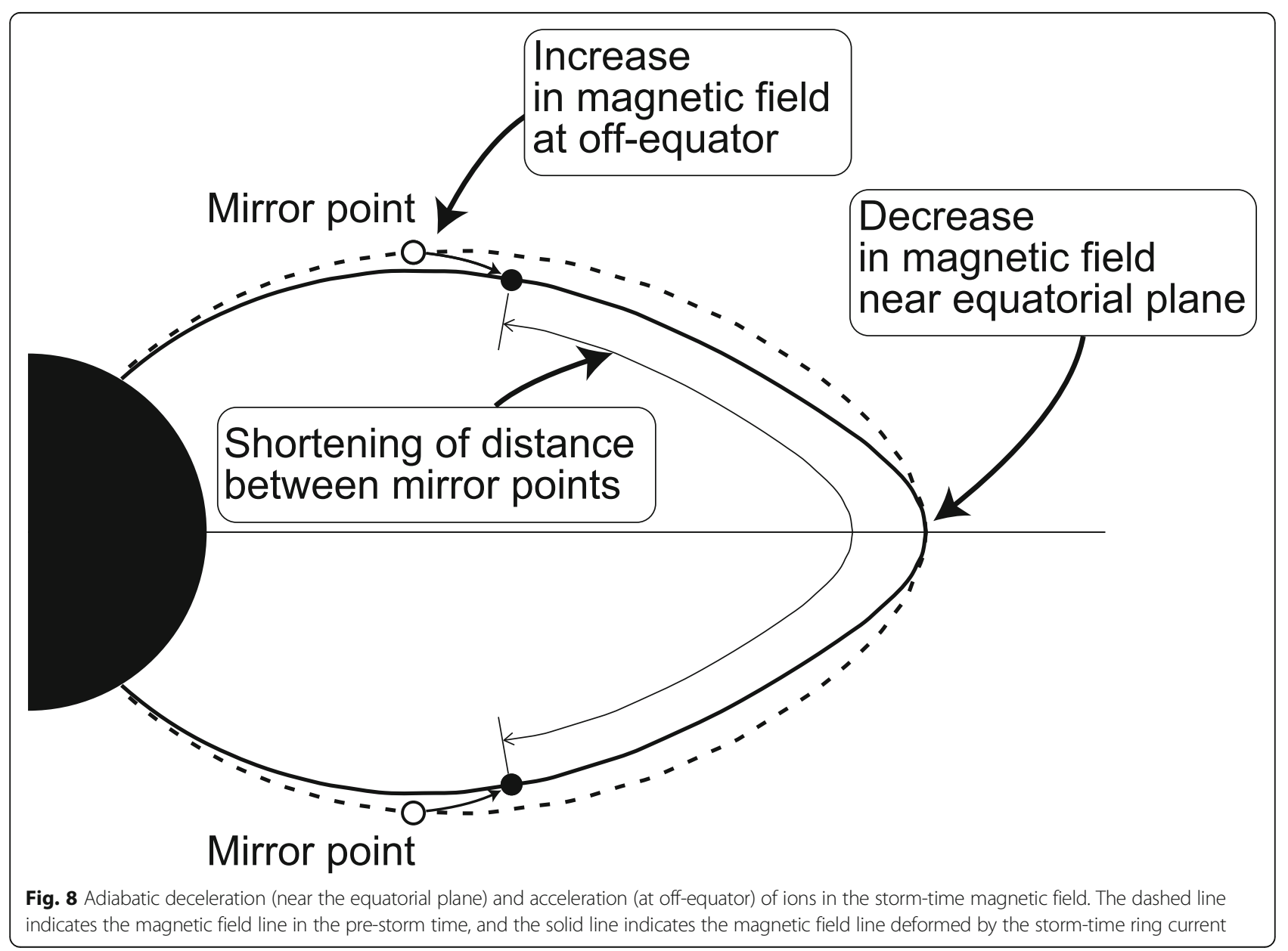




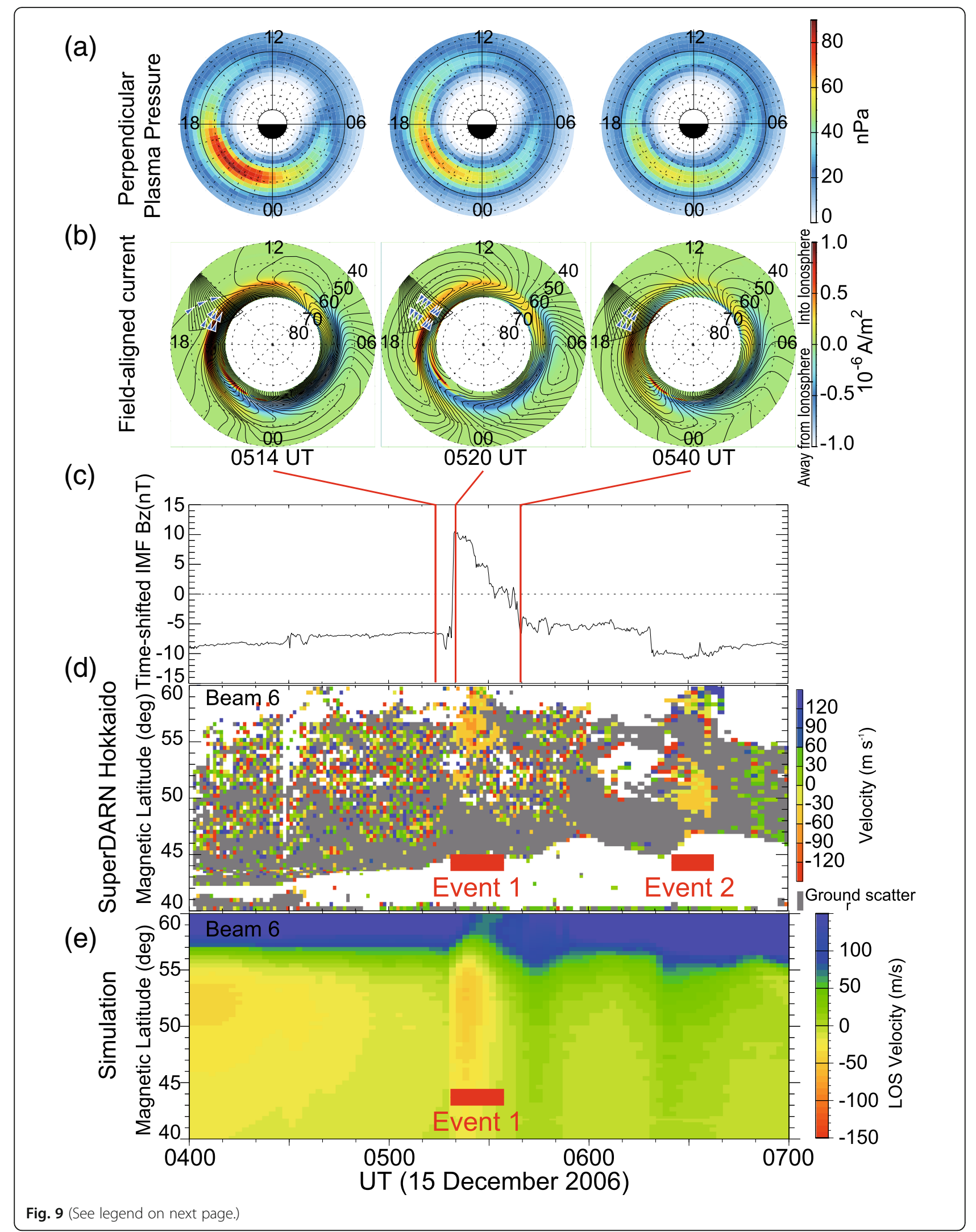


(See figure on previous page.)

Fig. 9 Example of ring current-ionosphere coupling (overshielding). In $\mathbf{b}$, the fan shape indicates the field of view of the SuperDARN Hokkaido radar, and the contour indicates the ionospheric electric potential. (After Ebihara et al. 2008b). a Simulated plasma pressure in the equatorial plane. b Simulated fieldaligned current in the ionosphere and electric potential. c Observed IMF Bz d Observed line-of-sight velocity. e Simulated line-of-sight velocity

et al. 2018). The field-line curvature (FLC) scattering occurs where the curvature of a magnetic field line is short in comparison with the gyroradius of the particle (Sergeev et al. 1983; Birmingham 1984; Büchner and Zelenyi 1989; Young et al. 2002). Using empirical magnetic field model, one can predict the region where the FLC scattering occurs. For example, the ratio of the gyroradius of a $50 \mathrm{keV} \mathrm{H}^{+}$to the curvature radius of the field line exceeds 0.1 at $L \sim 4.8$, and 1 at $L \sim 5.5$ for a large storm condition as shown in Fig. 5 (Ebihara et al. 2011). Strong pitch angle scattering is expected to occur in such limited regions.

Figure 6 shows the calculated Dst together with observed one. The Dst is calculated by comprehensive ring current model (CRCM) (Fok et al. 2001) together with self-consistent magnetic field (Ebihara et al. 2008a). Run 1 takes into account the charge exchange and the FLC scattering, showing that Dst recovers with an $e$-folding time of $\sim 3 \mathrm{~h}$. The difference between the observation and the simulation is probably attributed to the underestimation of the plasma sheet density. Run 2 takes into account the charge exchange only. The $e$-folding time is $\sim 12 \mathrm{~h}$. Obviously, inclusion of the FLC scattering appears to give rise to rapid recovery of Dst. However, the impact of the FLC scattering on the rapid recovery of Dst may be limited to small and moderate magnetic storms. For large magnetic storms, the inner edge of the ring current could reach very close to the Earth, like $L \sim 1.5$ (Ebihara et al. 2005a). In the deep inner region $(L<3)$, the magnetic field is rigid (that is, low plasma beta), so that the magnetic field is hardly stretched.

Precipitation of particles can occur without pitch angle scattering. The adiabatic loss cone loss, which arises when

$$
\frac{d \alpha_{L}}{d L}<\frac{d \alpha_{0}}{d L}
$$

where $\alpha_{L}$ and $\alpha_{0}$ are the loss cone angle and the equatorial pitch angle. As an ion moves earthward adiabatically, the equatorial pitch angle becomes large to conserve the first two adiabatic invariants. The loss cone angle also becomes large. As the ion moves earthward, the loss cone angle increases faster than the equatorial pitch angle does (Ebihara and Ejiri 2003). Some of the ions with equatorial pitch angle near the loss cone will precipitate into the ionosphere as the ions drift earthward. The contribution from the adiabatic loss cone loss is estimated to be very small (Jordanova et al. 1997). It amounts to $\sim 1-2 \%$ of the net loss of the ring current (Ebihara and Ejiri 2003).
Alternative idea to explain the rapid decay of the ring current is a replacement of the ring current population with tenuous one. This can be achieved when the plasma sheet density rapidly decreases and the convection electric field remains high (Ebihara and Ejiri 1998; Ebihara and Ejiri 2000). During the large magnetic storm on 20-21 November 2003, the rapid recovery of Dst can be explained by the sudden decrease in the plasma sheet density $N_{\mathrm{ps}}$ as shown in Fig. 1 (Ebihara et al. 2005a). When the plasma sheet density is constant in time, Dst shows slow recovery.

\section{Active role of ring current}

The ring current is strong enough to change the magnetic field in the inner magnetosphere (Akasofu and Chapman 1961). One of the observable effects of this is an adiabatic change in the trapped particles. Relativistic particle flux tends to decrease during the storm main phase, and increase during the recovery phase as if the flux follows the Dst variation (Mcllwain 1966). This is called a ring current effect. Satellite observations also show energy-dependent variation during the magnetic storms. The ion flux with energy greater than $200 \mathrm{keV}$ substantially decreases, whereas the ion flux with energy less than $63 \mathrm{keV}$ increases at $L \sim 4$ during an intense storm (Lyons and Williams 1976; Lyons 1977). The increase in the low-energy ions $(<63 \mathrm{keV})$ most likely corresponds to the storm-time ring current, which decreases the magnetic field near the equatorial plane, resulting in the adiabatic deceleration of the high energy ions (> $200 \mathrm{keV}$ ) (Williams 1981). This can be regarded as energy-domain coupling. Temporin and Ebihara (2011) show the similar tendency. They also show that during the recovery phase, the high-energy ion flux (125-173 keV) increases, and sometimes it exceeds the pre-storm level. This may imply the presence of non-adiabatic processes.

Figure 7 shows the pitch angle distribution of the protons and electrons measured by the Polar satellite near the equatorial plane (Ebihara et al. 2008a). The flux of protons (80-173 keV) and electrons (1.7-2.1 MeV) near the pitch angle of $\sim 90^{\circ}$ appears to decrease in comparison with the pre-storm condition. The simulated pitch angle distribution is shown in the bottom panels of Fig. 7. The differential flux of the ions is calculated by comprehensive ring current model (CRCM) (Fok et al. 2001) together with self-consistent magnetic field (Ebihara et al. 2008a). The flux near the pitch angle of $\sim 90^{\circ}$ decreases in comparison with the pre-storm condition, which is consistent with the observation (Lyons and Williams 1976; Lyons 1977). A remarkable point to be noted is the increase in the flux of 


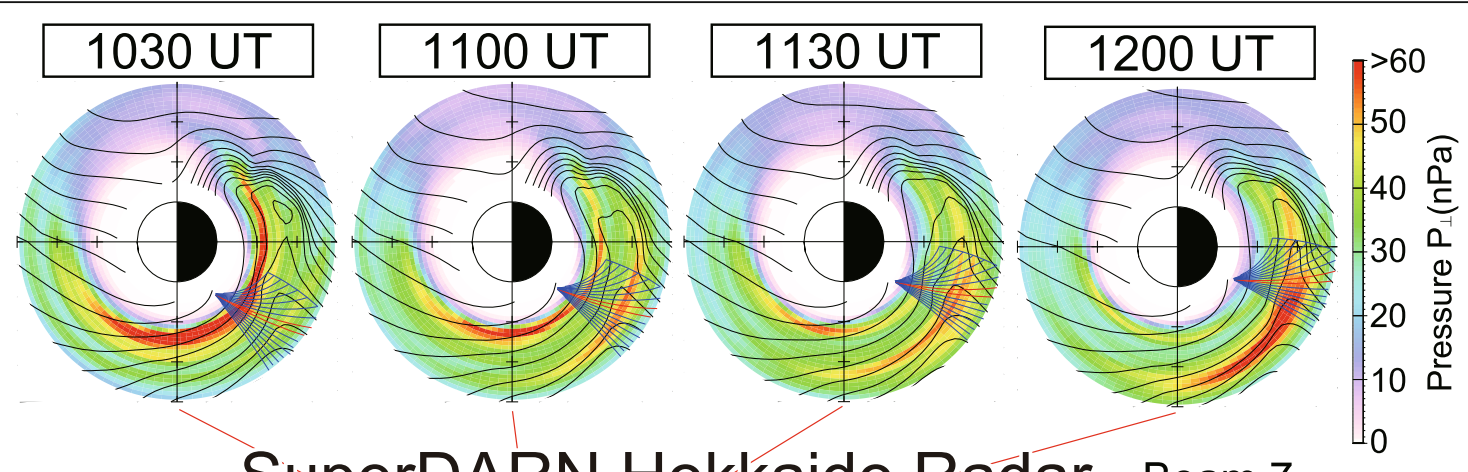

SuperDARN Hokkaido-Radar Beam 7
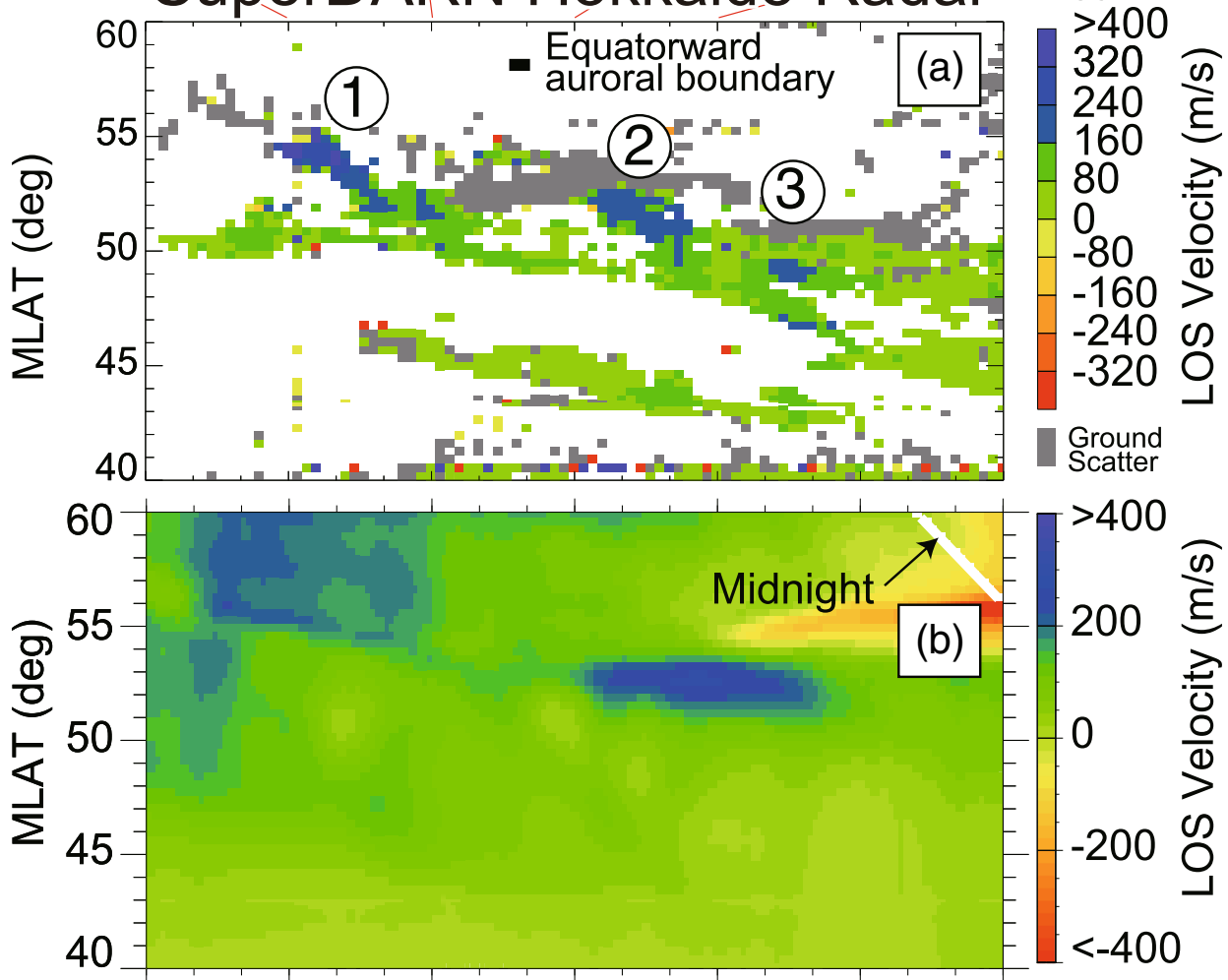

Ground

$>400$

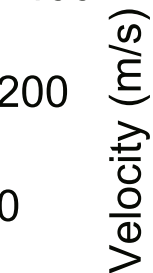

$-200$

O

60

$<-400$

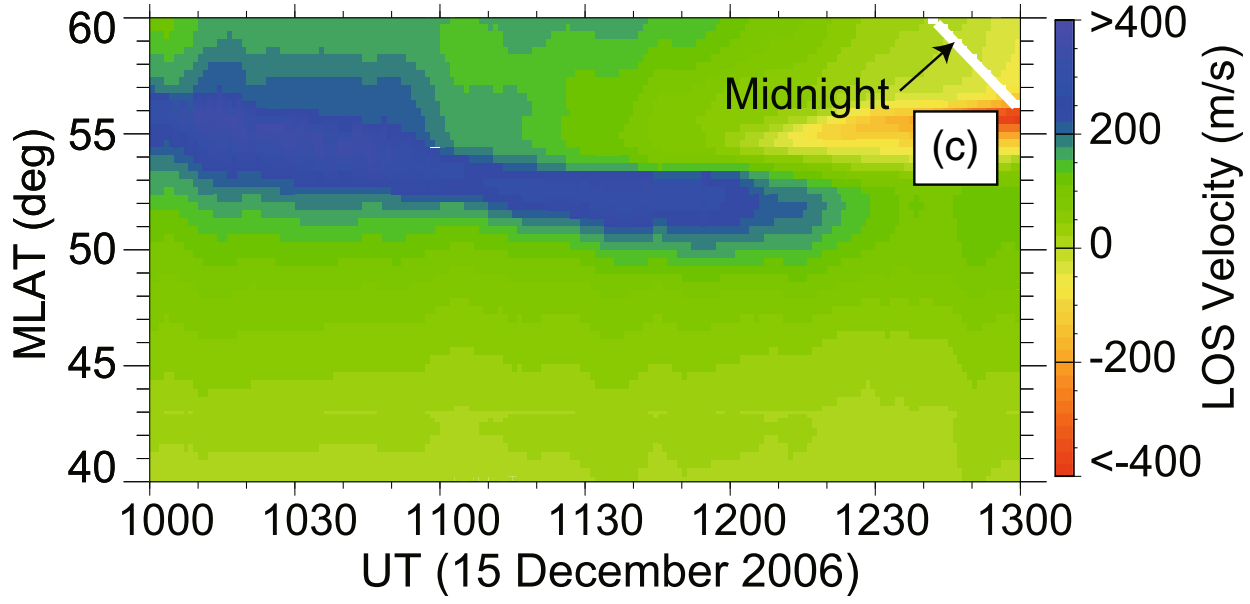

Fig. 10 Another example of ring current-ionosphere coupling (subauroral polarization stream). (After Ebihara et al. 2009). (top) Simulated plasma pressure. a SuperDARN Hokkaido radar observation of the line-of-sight velocity of ionospheric plasma flow. b Simulated line-of-sight velocity with time-varying plasma sheet density. c Simulated one with constant plasma sheet density 


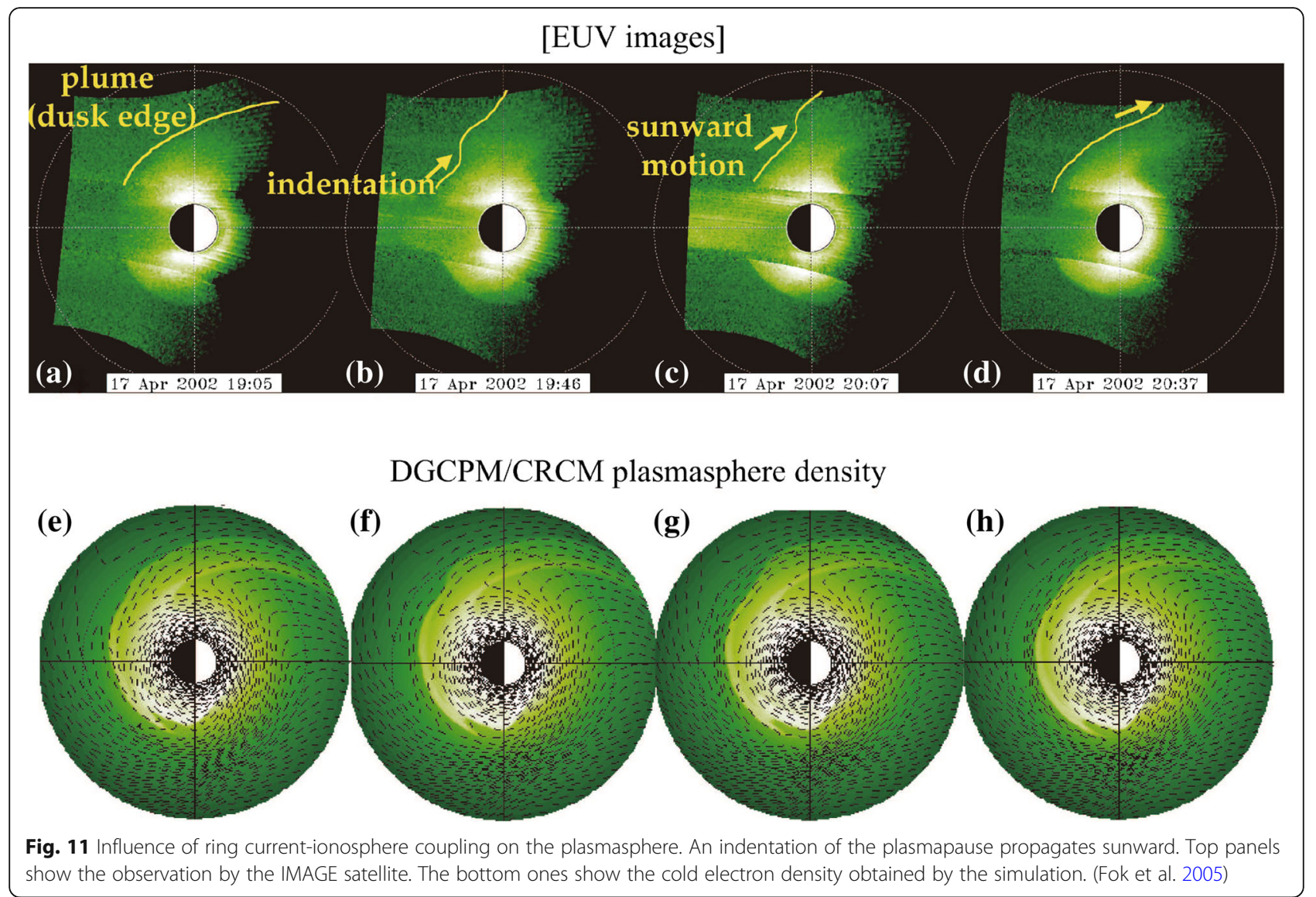

nearly field-aligned particles $\left(<30^{\circ}\right.$ and $\left.>150^{\circ}\right)$. The decrease (at pitch angles of $\sim 90^{\circ}$ ) and increase (at pitch angles of $<30^{\circ}$ and $>150^{\circ}$ ) in the flux of the ions correspond to deceleration and acceleration of the ions. The deceleration occurs near the equatorial plane where the magnetic field decreases. The acceleration occurs at off-equator where the magnetic field increases. The acceleration can also be explained in terms of Fermi acceleration because the distance between two mirror points in the Northern Hemisphere and the Southern Hemisphere becomes short. Figure 8 provides schematic illustration for the deceleration and

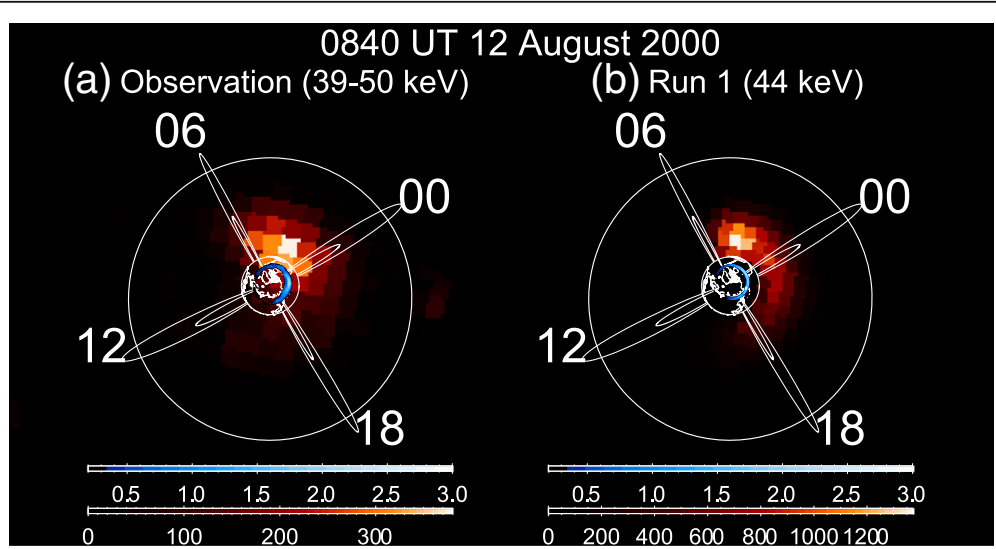

Fig. 12 Influence of ring current-ionosphere coupling on the ring current protons in terms of shielding. The flux of energetic neutral atoms is indicated by red color in the unit of $1 / \mathrm{cm}^{2} \mathrm{~s}$ str keV. Precipitating proton flux into the ionosphere is indicated by blue color in the unit of $10^{12} \mathrm{eV} / \mathrm{cm}^{2} \mathrm{~s}$. The left panel shows the observation made by the IMAGE satellite. The right one shows the simulation result. (Ebihara et al. 2011). a Observation (39-50 keV). b Simulation (44 keV) 


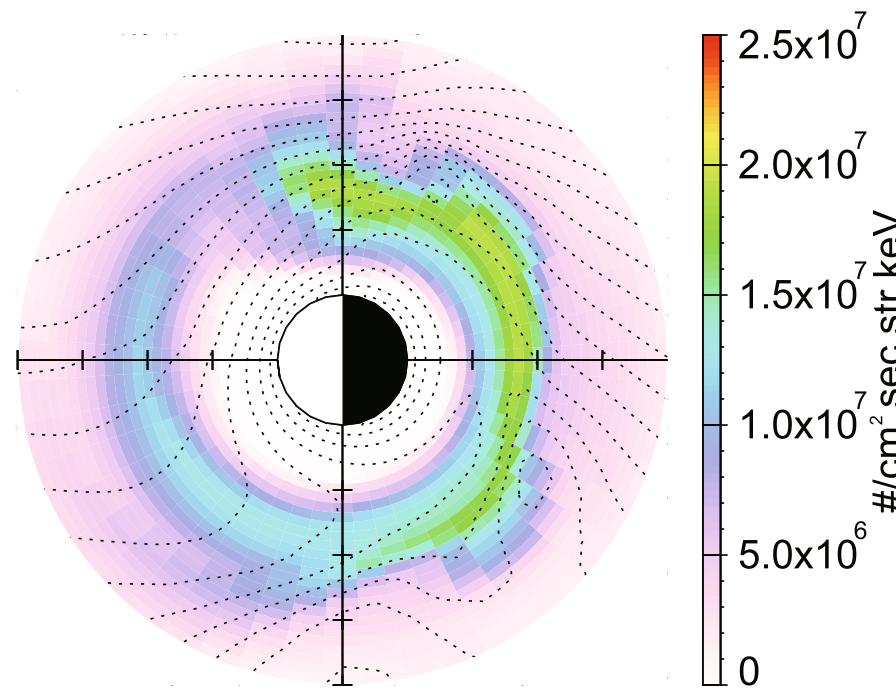

(1) Simulation 20 Nov 2003, 2140 UT

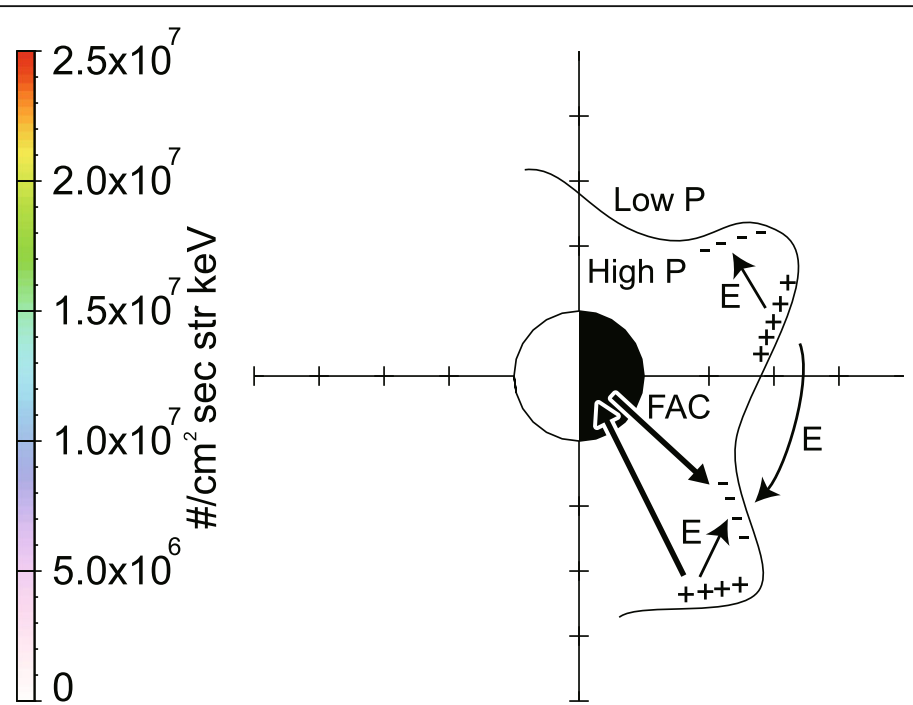

(2) Schematic representation

Fig. 13 Influence of ring current-ionosphere coupling on the ring current protons in terms of Rayleigh-Taylor type instability. Proton flux with energy $32 \mathrm{keV}$ is shown in the left panel. The outer edge of the flux population shows undulation due to interaction between the magnetosphere and the ionosphere. The contour indicates the ionospheric potential. The schematic illustration is provided in the right panel. (After Ebihara et al. 2005a)

acceleration of the charged particles in the magnetic field line changed by the ring current.

The current density of the ring current is stronger on the nightside than on the dayside during the magnetic storms (Le et al. 2004). This means that the storm-time ring current is essentially asymmetric, and that the current cannot be closed in the inner magnetosphere. From the requirement of the current continuity, the remnant of the current must flow into and out of the ionosphere as previously suggested by Hannes Alfvén (Egeland and Burke 2012). In the ionosphere, secondary electric field must be established to satisfy the current continuity. The electric field is expected to feed back to the magnetosphere. Motion of particles trapped in the inner magnetosphere will be modified by the additional electric field. This feedback process is suggested by Vasyliunas (1970) and Wolf (1970).

The ring current tends to generate downward FAC on the duskside, and upward FAC on the dawnside. A pair of these FACs is called region 2 current (Iijima and Potemra 1976). To close the current originating from the ring current, dusk-dawn electric field is expected to appear in the ionosphere. The direction of the electric field is opposite to that of the convection electric field. The additional electric field is called shielding electric field, and is substantially investigated by Spiro and Wolf (1984). Figure 9 shows an example of the ionospheric plasma flow associated with shielding electric field (Ebihara et al. 2008b). The second panel from the bottom shows the ionospheric plasma flow observed by the SuperDARN Hokkaido radar. The warm color represents the flow away from the radar, which is approximately in the geomagnetically north-east direction. The field of view of the radar was situated in the afternoon sector as shown in Fig. 9. The observation shows that the north-east flow (away from the radar) is intensified when IMF turns northward (event 1). The flow direction is opposite to the usually expected direction. This can be regarded as the overshieldling in which the shielding electric field dominates the convection electric field. The bottom panel shows the simulation result. The flow toward the radar is intensified, which is consistent with the observation for event 1 . In the second row from the top, the FACs associated with the ring current are provided, together with ionospheric convection pattern. The downward current (positive value) and the upward current (negative value) persist for this interval, whereas the ionospheric potential pattern is significantly changed by an abrupt reduction of the convection electric field. The direction of the ionospheric flow is changed from westward to eastward (as indicated by blue allows near a fan shape). The fan shape shows the field of views of the SuperDARN Hokkaido radar, which observed an abrupt intensification of the flow away from the radar. The plasma pressure in the inner magnetosphere, as shown in the top panel, decreases due to the dominance of the dusk-dawn electric field. The maximum pressure decreases from $\sim 90$ to $\sim 60$ $\mathrm{nPa}$ in $6 \mathrm{~min}$. After a while, another overshielding occurs during the prolonged southward IMF (event 2). Event 2 is 


\section{(1) Inflation of magnetosphere}

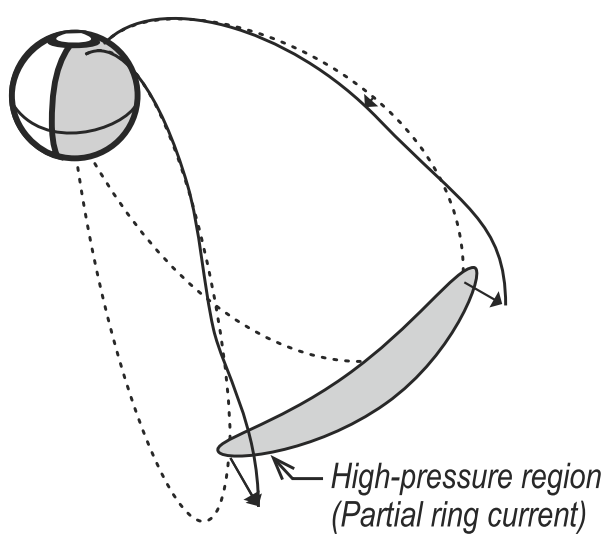

\section{(2) Shielding/overshielding}

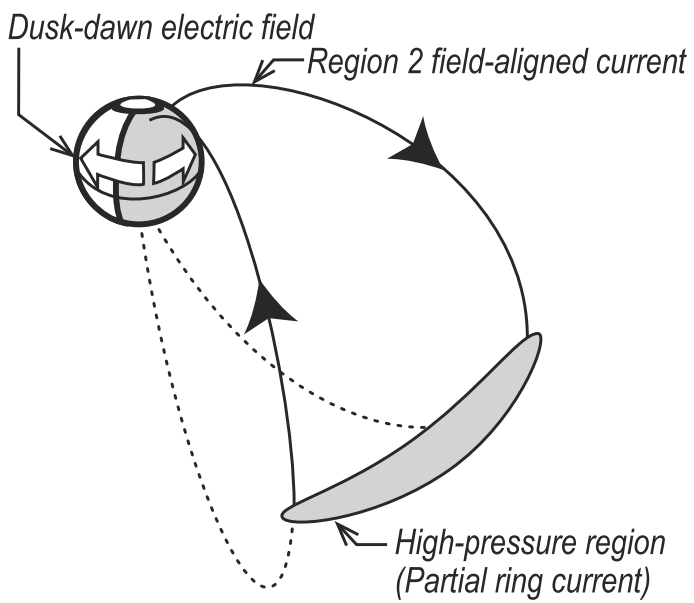

(3) Fast ionospheric flow

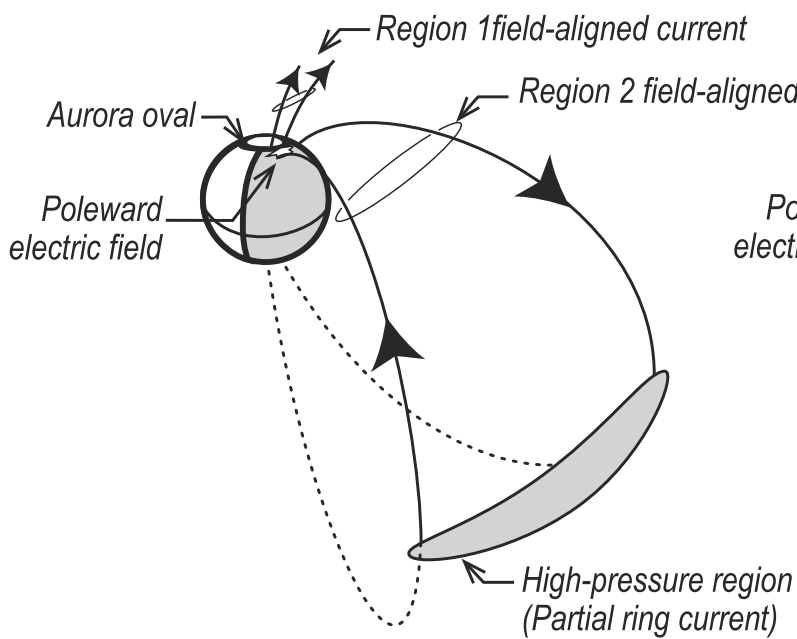

(4) Multiple fast ionospheric flows

ned current $\longleftarrow$ Region 1 field-aligned current

Fig. 14 Active role of the storm-time ring current; 1 inflation of the magnetic field, 2 development of the shielding/overshielding electric field (dusk-dawn electric field), 3 development of fast ionospheric flow (poleward electric field), and 4 development of multiple fast ionospheric flow (poleward electric field)

associated with a substorm activity, and is not reproduced by the ring current simulation (CRCM) that considers the inner magnetosphere only. Later on, the global MHD simulation, REPPU, is found to reproduce the overshielding condition during the recovery phase of a substorm (Ebihara et al. 2014). The geomagnetic field variation associated with the overshielding is consistent with the observation.

Another observable effect of the ring current-ionosphere coupling is a localized westward flow in the subauroral ionosphere. Region 1 current flows poleward of the region 2 current. To satisfy the current continuity, the poleward electric field is established on the duskside, resulting in a localized westward flow in the subauroral ionosphere (Anderson et al. 1993). Figure 10 shows the SuperDARN Hokkaido radar observation of the ionospheric fast flow at magnetic latitudes from $\sim 50^{\circ}$ to $\sim 55^{\circ}$ (Ebihara et al. 2009). The direction of the fast flow is westward as indicated by blue color. The fast flow occurs intermittently, not continuously. The fast flow belongs to a class of subauroral polarization stream (SAPS) (Foster and Vo 2002). In the top panels of Fig. 10, the plasma pressure distribution calculated by the CRCM simulation is shown. The simulation employs time-varying plasma sheet density observed by 


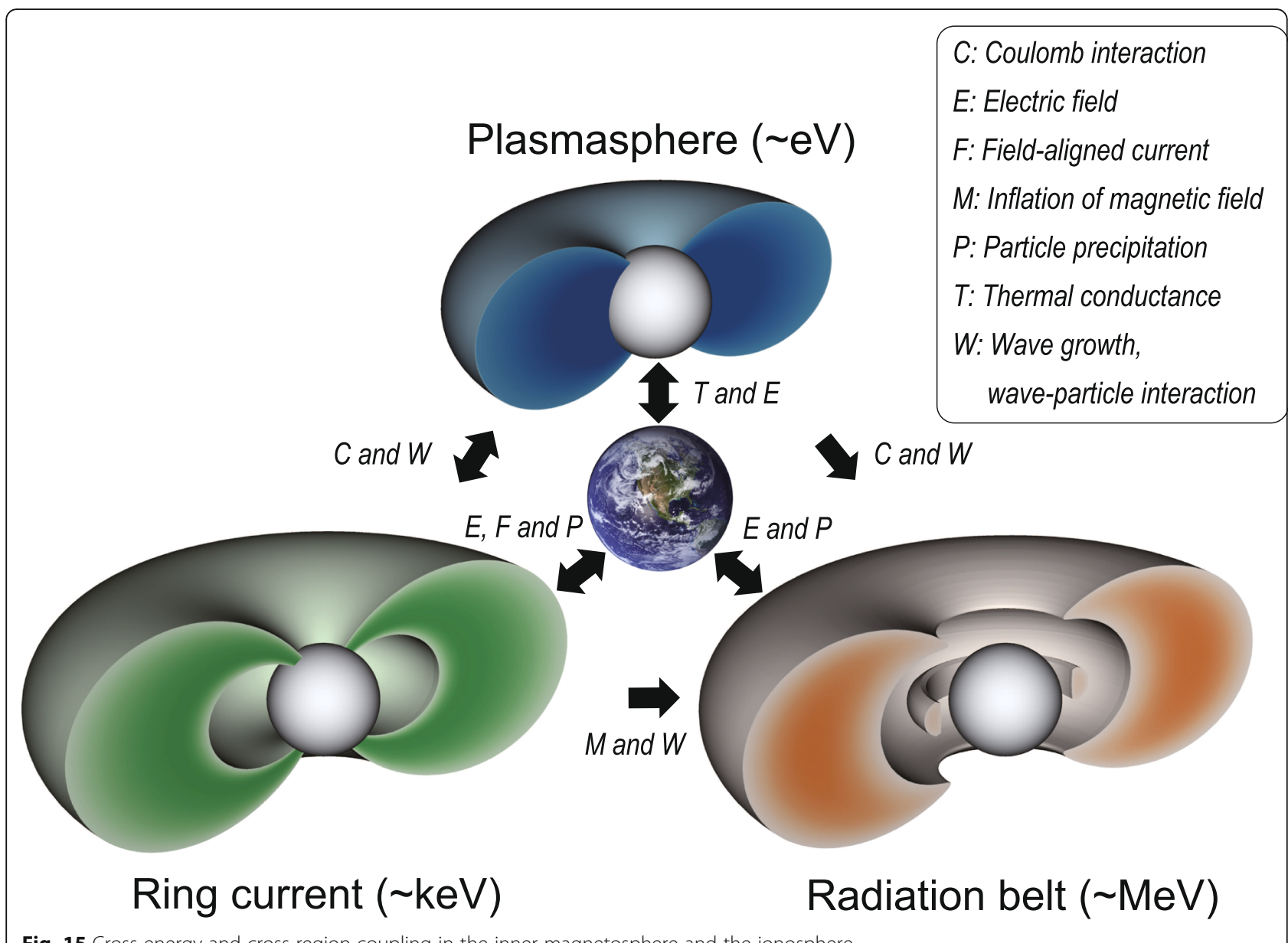

Fig. 15 Cross energy and cross region coupling in the inner magnetosphere and the ionosphere

geosynchronous satellites as a boundary condition of the ring current. Because of the time-varying plasma sheet density, the plasma pressure shows multiple-peak distribution. The multiple-peak distribution of plasma pressure moves earthward due to the sunward convection. The FAC accompanied by the plasma pressure distribution also moves westward equatorward. As the FAC moves, the electric field changes accordingly. In the third panel, the calculated line-of-sight velocity of the ionospheric plasma is provided, which is roughly consistent with the observation. When the plasma sheet density is kept constant in time, the ionospheric flow is rather continuous as shown in the bottom panel of Fig. 10.

Figure 11 shows an example of the impact of the ring current-ionosphere coupling on the plasmasphere (Fok et al. 2005). The top panels show the plasmasphere observed by the IMAGE satellite. An indentation appears suddenly on the duskside, and propagates sunward. The bottom panels show the cold electron density calculated by the CRCM. When the plasma sheet density increases abruptly, the ring current grows locally, generating localized FACs.
The electric field associated with the localized FACs initiates the indentation propagating sunward. Thus, the indentation of the plasmasphere may be regarded as the ring current-plasmasphere coupling.

Figure 12 shows an example of the impact of the ring current-ionosphere coupling on the energetic protons in the inner magnetosphere (Ebihara et al. 2011). The red color indicates the flux of energetic neutral atom (ENA) with energy of $\sim 44 \mathrm{keV}$. The peak flux of ENA takes place in the post-midnight sector, which is different from the conventional understanding. Conventionally, the ions originating from the nightside plasma sheet gain the kinetic energy most in the pre-midnight sector where the ions get closer to the Earth, as shown in Fig. 3. Thus, the peak of the ENA is expected to take place in the pre-midnight sector. The eastward shift of the ENA peak as observed by the IMAGE satellite can be explained by the development of the shielding electric field (Fok et al. 2003). The shielding electric field changes the drift trajectories, and some ions originating in the plasma sheet get closer to the Earth in the post-midnight sector. 
The ring current-ionosphere interaction can lead to a Rayleigh-Taylor type instability (interchange-like instability) (Sazykin et al. 2002; Ebihara et al. 2005a). Figure 13 shows the differential flux of protons with energy $32 \mathrm{keV}$ for the intense magnetic storm of 20-21 November 2003. CRCM is used to calculate the ions, and plasma sheet density and temperature observed at geosynchronous orbit are used as a boundary condition of the simulation. A remarkable point is the spatial distribution of the flux showing undulation. At the early stage of the recovery phase of this storm, the plasma sheet density suddenly decreases as shown in Fig. 1. Then, tenuous ion population propagates earthward. Consequently, the earthward gradient of the plasma pressure is established near the interface between the outer edge of the preexisting high-pressure (dense plasma) and the inner edge of the newly coming low-pressure (tenuous plasma). When the interface has a small hump, localized FACs are generated around it. Downward FAC flows on the westside of the hump, and upward one flows on the eastside. To satisfy the current continuity, eastward electric field is generated. When the eastward electric field is mapped to the magnetosphere, the ions that are constitute of the hump start drifting outward so as to enlarge the hump. This process is schematically illustrated in the right panel of Fig. 13.

The ring current is also known to result in auroral phenomena. The energy of the ring current ions is transferred to plasmaspheric thermal electrons by way of the Coulomb collisions. The heat flux propagates to the ionosphere, resulting in stable auroral red (SAR) arcs (Cole 1965). ENAs originating from the ring current ions precipitate into the ionosphere, resulting in aurora at low latitudes (Zhang et al. 2006). Magnitude of the lowlatitude aurora is inversely proportional to the Dst index. Temperature anisotropy of the ring current ions excites electromagnetic ion cyclotron (EMIC) waves (Kennel and Petschek 1966). The cold and hot plasma densities determine the linear growth rate of the EMIC wave. The pitch angle of the protons is scattered when they encounter the EMIC waves. Some of the scattered protons precipitate into the ionosphere, resulting in the proton aurora (Yahnin et al. 2007). Jordanova et al. (2007) calculated wave gain of the EMIC waves in the ring current simulation, and confirmed that the EMIC waves grow efficiently in the regions where the energetic ring current protons overlaps with the dayside plasmaspheric plumes and where density gradients are steep at the plasmapause. The precipitating protons significantly increase the ionospheric conductivity proton near the equatorward edge of the auroral oval on the duskside (Galand and Richmond 2001).

The ring current is shown to have a large influence on the magnetosphere and the ionosphere. Figure 14 summarizes the active role of the ring current. (1) The ring current is strong enough to distort the magnetic field, leading to adiabatic changes in the trapped particle fluxes. The magnetic field decreases near the equatorial plane, whereas the magnetic field increases at off-equator. This causes the dual acceleration process (betatron deceleration and Fermi acceleration), resulting in butterfly-like pitch angle distribution of trapped particles (Ebihara et al. 2008a). (2) The asymmetric ring current results in a formation of the region 2 FAC (flowing into the ionosphere on the duskside and away from the ionosphere on the dawnside). Dusk-dawn electric field appears to establish the current continuity in the ionosphere. This electric field is called a shielding/overshielding electric field because the direction is opposite to that of the convection electric field (dawn-dusk electric field). (3) The region 2 FAC is located equatorward of the region 1 FAC. Poleward electric field appears to establish the current continuity in the ionosphere. The poleward electric field gives rise to the westward fast ionospheric flow in the subauroral ionosphere. (4) When the plasma pressure shows multiple-peak distribution, multiple fast ionospheric flow appears. One observes changes in the speed of the ionospheric flow as the multiple plasma pressure distribution drifts.

Figure 15 summarizes possible cross energy and cross region coupling in the inner magnetosphere and the ionosphere. One causes another, so that the system is rather complicated. When the magnetic storms take place, all these components play active and passive roles. Numerical simulation is obviously a powerful tool to understand the complicated system.

\section{Conclusion}

The development and the decay of the magnetic storm are understood to accumulation and loss of the charged particles trapped by the Earth's magnetic field, respectively. The enhancement of the convection electric field is necessary to explain the accumulation of the particles and the development of the ring current during the magnetic storms. The ring current is strong enough to change the magnetic field in the near-Earth space environment, resulting in the significant changes in the trapped particles. The asymmetric distribution of the ring current, which can be reasonably explained by the development of the convection, results in the formation of the field-aligned current. The field-aligned current flows into and away from the ionosphere, giving rise to additional electric field. The simulation demonstrates that the ring current is not a consequence, but can be a cause of many observable effects during the magnetic storms.

\section{Abbreviations \\ ENA: Energetic neutral atom; FAC: Field-aligned current}

\section{Acknowledgements}

A part of the computer simulation was performed on the KDK computer system at Research Institute for Sustainable Humanosphere, Kyoto University. The author thanks Drs. Atsuhiro Nishida, Takashi Tanaka, Masaki Ejiri, Takashi 
Kikuchi, Mei-Ching H. Fok, Richard A. Wolf, Pontus C:son Brandt, Nozomu Nishitani, Tadahiko Ogawa, Lynn M. Kistler, and Hans Nilsson for fruitful discussion and valuable suggestion.

\section{Funding}

This work was supported by JSPS KAKENHI Grant Number $15 \mathrm{H} 03732$ and 15H05815, as well as Flagship Collaborative Research and Research Mission 3 "Sustainable Space Environments for Humankind" at RISH, Kyoto University,

\section{Availability of data and materials}

This is a review paper. All data used here are in the original papers cited in the text.

\section{Authors' contributions}

The author read and approved the final manuscript.

\section{Competing interests}

The author declares that he has no competing interests.

\section{Publisher's Note}

Springer Nature remains neutral with regard to jurisdictional claims in published maps and institutional affiliations.

Received: 5 October 2018 Accepted: 21 January 2019

Published online: 13 February 2019

\section{References}

Akasofu SI (1968) Polar and magnetospheric substorms. D. Reidel Publ. Co., Dordrecht

Akasofu SI, Chapman S (1961) The ring current, geomagnetic disturbance, and the Van Allen radiation belts. J Geophys Res 66:1321-1350. https://doi.org/10. 1029/JZ066i005p01321

Akasofu SI, Chapman S (1964) On the asymmetric development of magnetic storm fields in low and middle latitudes. Planet Space Sci 12:607-626. https://doi.org/10.1016/0032-0633(64)90008-X

Amundsen R, Søraas F, Lindalen HR, Aarsnes K (1972) Pitch-angle distributions of 100- to 300-kev protons measured by the Esro IB satellite. J Geophys Res 77: 556-566. https://doi.org/10.1029/JA077i004p00556

Anderson PC, Hanson WB, Heelis RA, Craven JD, Baker DN, Frank LA (1993) A proposed production model of rapid subauroral ion drifts and their relationship to substorm evolution. J Geophys Res 98:6069. https://doi.org/10. 1029/92JA01975

Axford WI (1969) Magnetospheric convection. Rev Geophys 7:421-459. https:// doi.org/10.5636/jgg.43.Supplement1 183

Birmingham TJ (1984) Pitch angle diffusion in the Jovian magnetodisc. J Geophys Res 89:2699. https://doi.org/10.1029/JA089iA05p02699

Borovsky JE, Denton MH (2006) Differences between CME-driven storms and CIR-driven storms. J Geophys Res Sp Phys 111:1-17. https://doi.org/10.1029/ 2005JA011447

Brandt PC, Mitchell DG, Ebihara Y, Sandel BR, Roelof EC, Burch JL, Demajistre R (2002) Global IMAGE/HENA observations of the ring current-examples of rapid response to IMF and ring current-plasmasphere interaction. J Geophys Res Sp Phys 107:1-12. https://doi.org/10.1029/2001JA000084

Büchner J, Zelenyi LM (1989) Regular and chaotic charged particle motion in magnetotaillike field reversals: 1. Basic theory of trapped motion. J Geophys Res 94:11821. https://doi.org/10.1029/JA094iA09p11821

Burton RK, McPherron RL, Russell CT (1975) An empirical relationship between interplanetary conditions and Dst. J Geophys Res 80:4204-4214. https://doi. org/10.1029/JA080i031p04204

Chen MW, Roeder JL, Fennell JF, Lyons LR, Schulz M (1998) Simulations of ring current proton pitch angle distributions. J Geophys Res Sp Phys 103:165-178. https://doi.org/10.1029/97JA02633

Cole KD (1965) Stable auroral red arcs, sinks for energy of D st main phase. J Geophys Res 70:1689-1706. https://doi.org/10.1029/JZ070i007p01689

Cornwall, JM, Coroniti, FV, Thorne RM (1970) Turbulent loss of ring current protons. J Geophys Res 75:4699-4709. https://doi.org/10.1029/ JA075i025p04699.

DeForest SE, Mcllwain CE (1971) Plasma clouds in the magnetosphere. J Geophys Res 76:3587-3611. https://doi.org/10.1029/JA076i016p03587

Denton MH, Borovsky JE, Skoug RM, Thomsen MF, Lavraud B, Henderson MG, McPherron RL, Zhang JC, Liemohn MW (2006) Geomagnetic storms driven by ICME- and CIR-dominated solar wind. J Geophys Res Sp Phys 111:1-12. https://doi.org/10.1029/2005JA011436

Dessler AJ, Parker EN (1959) Hydromagnetic theory of geomagnetic storms. J Geophys Res 64:2239-2252. https://doi.org/10.1029/JZ064i012p02239

Ebihara Y, Ejiri M (1998) Modeling of solar wind control of the ring current buildup: a case study of the magnetic storms in April 1997. Geophys Res Lett 25:3751-3754. https://doi.org/10.1029/1998GL900006

Ebihara Y, Ejiri M (2000) Simulation study on fundamental properties of the storm-time ring current. J Geophys Res 105:15843

Ebihara Y, Ejiri M (2003) Numerical simulation of the ring current: review. Space Sci Rev 105:377-452. https://doi.org/10.1023/A:1023905607888

Ebihara Y, Ejiri M, Nilsson H, Sandahl I, Milillo A, Grande M, Fennell JF, Roeder JL (2002) Statistical distribution of the storm-time proton ring current: POLAR measurements. https://doi.org/10.1029/2002GL015430

Ebihara, Y, Ejiri, M, Sandahl, I, Nilsson, H, Grande, M, Fennell, JF, Roeder, JL, Ganushkina, NYu, Millilo, A. (2004) Structure and dynamics of the proton energy density in the inner magnetosphere. 33:711-718. https://doi.org/10. 1016/S0273-1177(03)00632-X.

Ebihara Y, Fok MC, Blake JB, Fennell JF (2008a) Magnetic coupling of the ring current and the radiation belt. J Geophys Res Phys. https://doi.org/10.1029/2008ja013267

Ebihara Y, Fok MC, Immel TJ, Brandt PC (2011) Rapid decay of storm time ring current due to pitch angle scattering in curved field line. J Geophys Res Phys. https://doi.org/10.1029/2010ja016000

Ebihara Y, Fok MC, Sazykin S, Thomsen MF, Hairston MR, Evans DS, Rich FJ, Ejiri M (2005a) Ring current and the magnetosphere-ionosphere coupling during the superstorm of 20 November 2003. J Geophys Res Sp Phys 110:1-16. https://doi.org/10.1029/2004JA010924

Ebihara Y, Fok MC, Wolf RA, Thomsen MF, Moore TE (2005b) Nonlinear impact of plasma sheet density on the storm-time ring current. J Geophys Res Sp Phys 110:1-9. https://doi.org/10.1029/2004JA010435

Ebihara Y, Nishitani N, Kikuchi T, Ogawa T, Hosokawa K, Fok M-C (2008b) Two-dimensional observations of overshielding during a magnetic storm by the super dual Auroral radar network (SuperDARN) Hokkaido radar. J Geophys Res Sp Phys. https://doi.org/10.1029/2007JA012641

Ebihara Y, Nishitani N, Kikuchi T, Ogawa T, Hosokawa K, Fok M-C, Thomsen MF (2009) Dynamical property of storm time subauroral rapid flows as a manifestation of complex structures of the plasma pressure in the inner magnetosphere. J Geophys Res Sp Phys. https://doi.org/10.1029/2008JA013614

Ebihara Y, Tanaka T, Kikuchi T (2014) Counter equatorial electrojet and overshielding after substorm onset: global MHD simulation study. J Geophys Res Sp Phys 119:7281-7296. https://doi.org/10.1002/2014JA020065

Egeland A, Burke WJ (2012) The ring current: a short biography. Hist Geo Space Sci 3:131-142. https://doi.org/10.5194/hgss-3-131-2012

Ejiri M (1978) Trajectory traces of charged particles in the magnetosphere. J Geophys Res 83:4798. https://doi.org/10.1029/JA083iA10p04798

Ejiri M (1981) Shielding of the magnetospheric convection electric field and energetic charged particle penetrations towards the Earth. Paper presented at 1980 ISAS Symposium on Magneto-lonosphere, Inst. of Space and Astronaut. Sci., Tokyo

Fok MC, Ebihara Y, Moore TE, Ober DM, Keller KA (2005) Geospace storm processes coupling the ring current, radiation belt and plasmasphere. In: Burch J (ed) Geophysical monograph. American Geophysical Union Washington, D. C, pp 207-220

Fok, MC, Kozyra, JU, Nagy, AF, Cravens, TE (1991) Lifetime of ring current particles due to coulomb collisions in the plasmasphere. J Geophys Res 96:7861-7867. https://doi.org/10.1029/90JA02620.

Fok M-C, Moore TE, Delcourt DC (1999) Modeling of inner plasma sheet and ring current during substorms. J Geophys Res Sp Phys 104:14557-14569. https:// doi.org/10.1029/1999JA900014

Fok M-C, Moore TE, Kozyra JU, Ho GC, Hamilton DC (1995) Three-dimensional ring current decay model. J Geophys Res 100:9619. https://doi.org/10.1029/94JA03029

Fok MC, Moore TE, Wilson GR, Perez JD, Zhang XX, Brandt PC, Mitchell DG, Roelof EC, Jahn J-M, Pollock CJ, Wolf RA (2003) Global ENA Image Simulations. Space Sci Rev 109:77-103. https://doi.org/10.1023/B:SPAC. $0000007514.56380 . f d$

Fok M-C, Wolf R, Spiro RW, Moore TE (2001) Comprehensive computational model of Earth's ring current. J Geophys Res 106:8417. https://doi.org/10 1029/2000JA000235

Foster JC, Vo HB (2002) Average characteristics and activity dependence of the subauroral polarization stream. J Geophys Res Sp Phys 107:1-10. https://doi. org/10.1029/2002JA009409 
Frank LA (1967) On the extraterrestrial ring current during geomagnetic storms. J Geophys Res 72:3753-3767. https://doi.org/10.1029/JZ072i015p03753

Galand M, Richmond AD (2001) lonospheric electrical conductances produced by auroral proton precipitation. J Geophys Res 106:117. https://doi.org/10.1029/ 1999JA002001

Gonzalez WD, Joselyn JA, Kamide Y, Kroehl HW, Rostoker G, Tsurutani BT, Vasyliunas VM (1994) What is a geomagnetic storm? J Geophys Res 99:5771. https://doi.org/10.1029/93JA02867

Hairston MR, Drake KA, Skoug R (2005) Saturation of the ionospheric polar cap potential during the October-November 2003 superstorms. J Geophys Res Sp Phys 110:1-12. https://doi.org/10.1029/2004JA010864

Hamilton DC, Gloeckler G, Ipavich FM, Wilken B, Stuedemann W (1988) Ring current development during the great geomagnetic storm of February 1986. J Geophys Res 93:14343-14355. https://doi.org/10.1029/JA093iA12p14343

Hashimoto KK, Kikuchi T, Ebihara Y (2002) Response of the magnetospheric convection to sudden interplanetary magnetic field changes as deduced from the evolution of partial ring currents. J Geophys Res 107:1337. https:// doi.org/10.1029/2001JA009228

Hultqvist B, Riedler W, Borg H (1976) Ring current protons in the upper atmosphere within the plasmasphere. Planet Space Sci 24:783-797. https:// doi.org/10.1016/0032-0633(76)90115-X

lijima T, Potemra TA (1976) The amplitude distribution of field-aligned currents at northern high latitudes observed by triad. J Geophys Res 81:2165. https://doi. org/10.1029/JA081i013p02165

Jordanova VK, Farrugia CJ, Thorne RM, Khazanov GV, Reeves GD, Thomsen MF (2001) Modeling ring current proton precipitation by electromagnetic ion cyclotron waves during the May 14-16, 1997, storm. J Geophys Res 106:7. https://doi.org/10.1029/2000JA002008

Jordanova VK, Kistler LM, Kozyra JU, Khazanov GV, Nagy AF (1996) Collisional losses of ring current ions. J Geophys Res 101:111. https://doi.org/10.1029/95JA02000

Jordanova VK, Kozyra JU, Nagy AF, Khazanov GV (1997) Kinetic model of the ring current-atmosphere interactions. J Geophys Res 102:14279

Jordanova VK, Spasojevic M, Thomsen MF (2007) Modeling the electromagnetic ion cyclotron wave-induced formation of detached subauroral proton arcs. J Geophys Res Sp Phys 112:1-13. https://doi.org/ 10.1029/2006JA012215

Kamide Y, Mcllwain CE (1974) The onset time of magnetospheric substorms determined from ground and synchronous satellite records. J Geophys Res 79:4787-4790

Kamide Y, Yokoyama N, Gonzalez W, Tsurutani BT, Daglis IA, Brekke A, Masuda S (1998) Two-step development of geomagnetic storms. J Geophys Res Sp Phys 103:6917-6921. https://doi.org/10.1029/97JA03337

Kennel CF, Petschek HE (1966) Limit on stably trapped particle fluxes. J Geophys Res 71:1-28. https://doi.org/10.1029/JZ0711001p00001

Kokubun S (1972) Relationship of interplanetary magnetic field structure with development of substorm and storm main phase. Planet Space Sci 20: 1033-1049. https://doi.org/10.1016/0032-0633(72)90214-0

Kozyra JU, Fok M-C, Sanchez ER, Evans DS, Hamilton DC, Nagy AF (1998a) The role of precipitation losses in producing the rapid early recovery phase of the great magnetic storm of February 1986. J Geophys Res 103:6801. https:// doi.org/10.1029/97JA03330

Kozyra JU, Jordanova VK, Borovsky JE, Thomsen MF, Knipp DJ, Evans DS, McComas DJ, Cayton TE (1998b) Effects of a high-density plasma sheet on ring current development during the November 2-6, 1993, magnetic storm. J Geophys Res 103:26285. https://doi.org/10.1029/98JA01964

Lakhina GS, Tsurutani BT (2016) Geomagnetic storms: historical perspective to modern view. Geosci Lett. https://doi.org/10.1186/s40562-016-0037-4

Le G, Russell CT, Takahashi K (2004) Morphology of the ring current derived from magnetic field observations. Ann Geophys 22:1267-1295. https://doi.org/10. 5194/angeo-22-1267-2004

Lee LC, Corrick G, Akasofu S-I (1983) On the ring current energy injection rate. Planet Space Sci. https://doi.org/10.1016/0032-0633(83)90145-9

Liemohn MW, Kozyra JU, Jordanova VK, Khazanov GV, Thomsen MF, Cayton TE (1999) Analysis of early phase ring current recovery mechanisms during geomagnetic storms. Geophys Res Lett 26:2845-2848. https:/doi.org/10.1029/1999GL900611

Liemohn MW, Kozyra JU, Thomsen MF, Roeder JL, Lu G, Borovsky JE, Cayton TE (2001) Dominant role of the asymmetric ring current in producing the stormtime Dst *. J Geophys Res Sp Phys 106:10883-10904. https://doi.org/10. 1029/2000JA000326

Lui ATY, McEntire RW, Krimigis SM (1987) Evolution of the ring current during two geomagnetic storms. J Geophys Res 92:7459-7470. https://doi.org/10. 1029/JA092iA07p07459
Lyons LR (1977) Adiabatic evolution of trapped particle pitch angle distributions during a storm main phase. J Geophys Res 82:2428-2432. https://doi.org/10. 1029/JA082i016p02428

Lyons LR, Williams DJ (1976) Storm-associated variations of equatorially mirroring ring current protons, 1-800 keV, at constant first adiabatic invariant. J Geophys Res 81:216-220. https://doi.org/10.1029/JA081i001p00216

Macmahon RM, Llop-Romero C (2008) Ring current decay time model during geomagnetic storms: a simple analytical approach. Ann Geophys 26:2543-2550. https://doi.org/10.5194/angeo-26-2543-2008

Matsui H, Torbert RB, Spence HE, Khotyaintsev W, Lindqvist P-A (2013) Revision of empirical electric field modeling in the inner magnetosphere using cluster data. J Geophys Res Sp Phys 118:4119-4134. https://doi.org/10.1002/jgra.50373

Mcllwain CE (1966) Ring current effects on trapped particles. J Geophys Res 71: 3623-3628. https://doi.org/10.1029/JZ071i015p03623

Parker EN (1957) Newtonian development of the dynamical properties of ionized gases of low density. Phys Rev 107:924-933. https://doi.org/10.1103/PhysRev.107.924

Rairden RL, Frank L, Craven JD (1986) Geocoronal imaging with dynamics explorer. J Geophys Res 91:13613. https://doi.org/10.1029/JA091iA12p13613

Roederer JG (1970) Dynamics of geomagnetically trapped radiation. Springer Berlin Heidelberg, Berlin

Sazykin S, Wolf RA, Spiro RW, Gombosi TI, De Zeeuw DL, Thomsen MF (2002) Interchange instability in the inner magnetosphere associated with geosynchronous particle flux decreases. Geophys Res Lett. https://doi.org/10. 1029/2001GL014416

Sckopke N (1966) A general relation between the energy of trapped particles and the disturbance field near the Earth. J Geophys Res 71:3125-3130. https://doi.org/10.1029/JZ071i013p03125

Sergeev VA, Sazhina EM, Tsyganenko NA, Lundblad JÅ, Søraas F (1983) Pitch-angle scattering of energetic protons in the magnetotail current sheet as the dominant source of their isotropic precipitation into the nightside ionosphere. Planet Space Sci 31:1147-1155. https://doi.org/10.1016/0032-0633(83)90103-4

Siscoe GL (2002) Hill model of transpolar potential saturation: comparisons with MHD simulations. J Geophys Res 107:1075. https://doi.org/10.1029/ 2001JA000109

Smith PH, Hoffman RA (1973) Ring current particle distributions during the magnetic storms of December 16-18, 1971. J Geophys Res 78:4731-4737. https://doi.org/10.1029/JA078i022p04731

Spiro RW, Wolf RA (1984) Electrodynamics of convection in the inner magnetosphere. In: Potemra TA (ed) Magnetospheric Currents, Geophys. Monogr. Ser., vol 28. AGU, Washington, D. C, p 248

Stern DP (1975) The motion of a proton in the equatorial magnetosphere. https://doi.org/10.1029/JA080i004p00595

Sugiura M (1964) Hourly values of equatorial Dst for the IGY

Sugiura M, Kamei T (1991) Equatorial Dst index 1957-1986. IAGA Bull., vol. 40, ISGI Pub. Office, Saint-Maur-des-Fossess, France, p 7-14

Takahashi S, lyemori T, Takeda M (1990) A simulation of the storm-time ring current. Planet Space Sci 38:1133-1141. https://doi.org/10.1016/ 0032-0633(90)90021-H

Temporin A, Ebihara Y (2011) Energy-dependent evolution of ring current protons during magnetic storms. J Geophys Res 116:A10201. https://doi.org/ 10.1029/2011JA016692

Terasawa T, Fujimoto M, Mukai T, Shinohara I, Saito Y, Yamamoto T, Machida S, Kokubun S, Lazarus AJ, Steinberg JT, Lepping RP (1997) Solar wind control of density and temperature in the near-Earth plasma sheet: WIND/GEOTAIL collaboration. Geophys Res Lett 24:935-938. https:/doi.org/10.1029/96GL04018

Thébault E, Finlay CC, Beggan CD, Alken P, Aubert J, Barrois O, Bertrand F, Bondar T, Boness A, Brocco L, Canet E, Chambodut A, Chulliat A, Coïsson P, Civet F, Du A, Fournier A, Fratter I, Gillet N, Hamilton B, Hamoudi M, Hulot G, Jager T, Korte M, Kuang W, Lalanne X, Langlais B, Léger JM, Lesur V, Lowes FJ, Macmillan S, Mandea M, Manoj C, Maus S, Olsen N, Petrov V, Ridley V, Rother M, Sabaka TJ, Saturnino D, Schachtschneider R, Sirol O, Tangborn A, Thomson A, Tøffner-Clausen L, Vigneron P, Wardinski I, Zvereva T (2015) International geomagnetic reference field: the 12th generation international geomagnetic reference field - the twelfth generation. Earth Planets Space. https://doi.org/10.1186/s40623-015-0228-9

Toffoletto F, Sazykin S, Spiro R, Wolf R (2003) Inner magnetospheric modeling with the rice convection model. Space Sci Rev 107:175-196. https://doi.org/ 10.1023/A:1025532008047

Tsurutani BT, Gonzalez WD (1987) The cause of high-intensity longduration continuous AE activity (HILDCAAs): interplanetary Alfvén wave trains. Planet Space Sci 35:405-412. https://doi.org/10.1016/00320633(87)90097-3 
Tsurutani BT, Gonzalez WD, Tang F, Akasofu SI, Smith EJ (1988) Origin of interplanetary southward magnetic fields responsible for major magnetic storms near solar maximum (1978-1979). J Geophys Res 93:8519. https://doi. org/10.1029/JA093iA08p08519

Tsurutani BT, Lakhina GS, Echer E, Hajra R, Nayak C, Mannucci AJ, Meng X (2018) Comment on "modeling extreme 'Carrington-type' space weather events using three-dimensional global MHD simulations" by C. M. Ngwira, A. Pulkkinen, M. M. Kuznetsova, and A. Glocer. J Geophys Res Sp Phys 123:1388-1392. https://doi. org/10.1002/2017JA024779

Vasyliunas V (1970) Mathematical models of magnetospheric convection and its couplingt to the ionosphere. In: McCormac BM (ed) Particles and fields in the magnetosphere, New York, in Astrophysics and Space Science Library book series (ASSL, volume 17) pp 60-71, https://doi.org/10.1007/978-94-010-3284-1_6.

Volland H (1973) A semiempirical model of large-scale magnetospheric electric fields. J Geophys Res 78:171. https://doi.org/10.1029/JA078i001p00171

von Humboldt A (1808) Die vollständigste aller bisherigen Beobachtungen über den Einfluss des Nordlichts auf die Magnetnadel angestellt. Ann Phys 29:425-429. https://doi.org/10.1002/andp.18080290806

Walt M, Voss HD (2001) Losses of ring current ions by strong pitch angle scattering. Geophys Res Lett 28:3839-3841. https:/doi.org/10.1029/2001GL013425

Wentworth, RC, MacDonald, WM, Singer, SF (1959) Lifetimes of Trapped Radiation Belt Particles Determined by Coulomb Scattering. Phys of Fluids 2:499-509. https://doi.org/10.1063/1.1705940

Williams DJ (1981) Phase space variations of near equatorially mirroring ring current ions. J Geophys Res 86:189. https://doi.org/10.1029/JA086iA01 p00189

Williams DJ, Lyons LR (1974) The proton ring current and its interaction with the plasmapause: storm recovery phase. J Geophys Res 79:4195-4207. https://doi. org/10.1029/JA079i028p04195

Wodnicka EB (1989) The magnetic storm main phase modelling. Planet Space Sci 37:525-534. https://doi.org/10.1016/0032-0633(89)90093-7

Wolf RA (1970) Effects of ionospheric conductivity on convective flow of plasma in the magnetosphere. J Geophys Res 75:4677. https://doi.org/10.1029/JA075i025p04677

Yahnin AG, Yahnina TA, Frey HU (2007) Subauroral proton spots visualize the PC1 source. J Geophys Res 112:A10223. https://doi.org/10.1029/2007JA012501

Young SL, Denton RE, Anderson BJ, Hudson MK (2002) Empirical model for $\mu$ scattering caused by field line curvature in a realistic magnetosphere. J Geophys Res Sp Phys. https://doi.org/10.1029/2000JA000294

Zhang Y, Paxton LJ, Kozyra JU, Kil H, Brandt PC (2006) Nightside thermospheric FUV emissions due to energetic neutral atom precipitation during magnetic superstorms. I Geophys Res 111:A09307. https://doi.org/10.1029/2005JA011152

\section{Submit your manuscript to a SpringerOpen ${ }^{\circ}$ journal and benefit from:}

- Convenient online submission

- Rigorous peer review

- Open access: articles freely available online

- High visibility within the field

- Retaining the copyright to your article

Submit your next manuscript at $\boldsymbol{\nabla}$ springeropen.com 